\title{
Long-Term Optical Recording of Patterns of Electrical Activity in Ensembles of Cultured Aplysia Neurons
}

\author{
T. D. PARSONS, B. M. SAlZBERG, A. L. OBAID, F. RACCUIA-BEHLING, AND D. KLEINFELD \\ Department of Physiology, University of Pennsylvania School of Medicine, Philadelphia, Pennsylvania 19104-6085; \\ Marine Biological Laboratory, Woods Hole, Massachusetts 02543; and AT\&T Bell Laboratories, \\ Murray Hill, New Jersey 07974
}

\section{SUMMARY AND CONCLUSIONS}

1. Left upper quadrant (LUQ) cells isolated from the abdominal ganglion of Aplysia were maintained in culture to study how the cellular and synaptic properties of individual neurons contribute to the generation of patterns of electrical activity by neuronal ensembles.

2. Conventional microelectrodes were used to examine the spiking characteristics of individually cultured LUQ cells in vitro and to characterize their synaptic interactions.

3. In vitro, in contrast to in situ, LUQ neurons innervate other LUQ neurons. Intracellular recordings from pairs of LUQ cells showed that the prevalent type of postsynaptic potential was purely inhibitory. The other type of response was a dual-action postsynaptic potential, with inhibition followed by a delayed, slow excitation.

4. We established a set of criteria for the use of multiple-site optical recording techniques, in combination with impermeant probes of membrane potential, to observe the patterns of electrical activity generated by ensembles of co-cultured LUQ cells.

5. The spiking activity of individual cells within the neuronal ensembles was detected by means of the change in optical absorption of cells that were vitally stained with the dye RH155. The change in absorption was typically $\Delta A \simeq 4 \times 10^{-4}$ per spike. We achieved a signal-to-noise (peak-to-peak) ratio of $\sim 10$ for a $50 \times$ $50-\mu \mathrm{m}$ photodetector field and an incident intensity of $\sim 10 \mathrm{~mW}$ / $\mathrm{cm}^{2}$, close to the theoretical limit.

6. These conditions permitted, for the first time, continuous optical recording from cultured neurons for periods of up to $3 \mathrm{~h}$ with no discernible photodynamic damage or photobleaching. This long-term optical recording permitted examination of the different patterns of electrical activity generated by individual neuronal ensembles under several different experimental conditions.

7. An elaborate tracery of regenerated neurites present in these cultures resulted in individual photodetectors recording simultaneously the activity of multiple neurons. We reconstructed the temporal firing patterns for individual neurons within ensembles even with all of the neurons active simultaneously and determined the functional connections in the enscmble by analyzing the temporal relationships between firing patterns of individual neurons. Excitatory as well as inhibitory functional interactions could be observed within the neuronal ensemble, the latter after the tonic activity of the neurons was increased by reducing the extracellular $\left[\mathrm{Mg}^{2+}\right]$

8. Examination of the optical data from ensembles constructed from identified cells having characteristic physiological responses allowed us to address the question of how cellular and synaptic properties affect the patterns of electrical activity generated by neuronal ensembles. In one particularly interesting ensemble, the firing patterns observed when two cells were stimulated simultaneously were not predicted by the simple superposition of the firing patterns when the cells were stimulated individually. Activation of the individual cells revealed excitatory functional connec- tions. However, with pairwise stimulation, no functional connections were observed.

9. The dynamic patterns of functional connectivity exhibited within the neuronal ensembles we investigated may be attributed to the contributions of different cellular and synaptic properties of the participating LUQ cells. These studies illustrate how the cellular and synaptic properties of individual neurons, such as postburst hyperpolarization, inhibitory synapses, and dual-action synapses, can interact to generate multiple patterns of electrical activity within a single neuronal ensemble.

\section{INTRODUCTION}

A basic question in neurophysiology concerns the emergence of patterns of electrical activity in neuronal circuits. This question has been studied through a broad variety of experimental and theoretical approaches (e.g., Koch and Segev 1989; Lund 1989; Selverston 1985). At the systems level, patterns of activity are observed in nervous systems with repetitive architecture. Examples include localized activity in the visual cortex that coincides with the underlying columnar architecture (Blasdel 1989; Hubel and Wiesel 1977) and widespread, oscillatory activity in the olfactory cortex that tracks along the association fibers (Habcrly 1985). At the circuit level, patterns of activity among identified neurons have been studied primarily in motor systems of invertebrates (e.g., Delcomyn 1980; Getting 1989a; Kris$\tan 1980$ ) and in the mammalian spinal reflex arc (Burke and Rudomin 1977). The formation of output patterns in these circuits results from some combination of intrinsic cellular properties, the connection between neurons, and external inputs. The precise interplay among these features, however, has often been difficult to establish in in vivo preparations (e.g., Kleinfeld et al. 1991; Selverston 1980).

An alternative approach to studying the mechanisms that give rise to patterns of activity is to construct model circuits in cell culture. This approach allows simplificd circuits to be examined so that certain cellular and synaptic properties can be held constant while others are varied. Thus questions that could not be adequately addressed in situ can be examined with systems in cell culture. Examples are the analysis of circuits with multiple, persistent output states (Kleinfeld et al. 1990b) and the study of a reconstructed rhythmic pattern generator (Syed et al. 1990).

Here we address some aspects of the electrical activity that occurs in "defined" ensembles of cultured Aplysia neurons. We begin with the problem of simultaneous recording of the electrical activity of many neurons for extended pe- 
riods of time, using an approach based on potentiometric molecular probes and multiple-site optical recording techniques (e.g., Cohen and Salzberg 1978; Grinvald et al. 1988; Salzberg 1989; Salzberg et al. 1973, 1977, 1983).

Previous studies have established the feasibility of using optical techniques to record simultaneously the activity of many cells in in situ preparations (Grinvald et al. 1981a; London et al. 1987; Salzberg et al. 1977; Woolum and Strumwasser 1978; Yagodin et al. 1988; Zecevic et al. 1989). Studies using in vitro preparations are less developed. Ross and Reichardt (1979) first obtained optical recordings from vertebrate neurons in tissue culture. The work of Grinvald et al. (1981b) demonstrated that optical techniques can be used to record activity in cultures of neuroblastoma cells, albeit for very brief periods. Parsons et al. (1989a) showed that optical methods can be used to record the activity of synaptically interacting pairs of Aplysia neurons. This latter work suggested the utility of using optical methods with larger ensembles of cultured neurons.

The present work establishes that optical techniques can be used to record from identified Aplysia neurons in vitro for extended periods of time as long as $3 \mathrm{~h}$. Such long recording times are valuable for probing the interactions that occur in neuronal ensembles under a variety of experimental conditions. We demonstrate the feasibility of extracting the temporal firing patterns of individual cells within complex ensembles of at least six co-cultured neurons with intermingled neurites. The temporal firing patterns observed under different experimental conditions were used to infer sets of functional connections between the neurons (Aertsen et al. 1989). LUQ cells do not innervate each other in vivo (Frazier et al. 1967); however, they were observed to form inhibitory synapses and dual-action synapses in culture. We have exploited these results to study how the cellular and synaptic properties of individual identified neurons contribute to the generation of dynamic patterns of functional connectivity within a single neuronal ensemble.

Preliminary reports of this work have appeared (Kleinfeld et al. 1989; Obaid et al. 1989; Parsons et al. 1989b,d).

\section{METHODS}

Our procedures are modified from those described in Parsons et al. (1989a).

\section{Culture techniques}

Juvenile Aplysia californica $(1-5 \mathrm{~g})$ raiscd in mariculture were a gift of the Howard Hughes Medical Institute (Woods Hole, MA) or field collected by Sea Life Supply (San Diego, CA) or Marinus (Long Beach, CA). Left upper quadrant (LUQ) cells (Frazier et al. 1967) were isolated from the abdominal ganglion and maintained in cell culture as described (Dagan and Levitan 1981; Schacher and Proshansky 1983). Ensembles were formed by plating four to six LUQ cells on a first day and replacing dead cells on a second day. The neurons were initially arranged in the shape of an asterisk, with cell bodies on the outside and overlapping initial segments in the center. For some experiments we isolated neuron R15; this cell was identified by its anatomic location (Frazier et al. 1967) and known cellular properties (Strumwasser 1965).

The ensembles were photographed using Hoffman modulation optics (Modulation Optics, New York, NY) immediately prior to the optical measurements. This allowed us to visualize the spatial distribution of the regenerated neurite outgrowth.

\section{Solutions}

All staining procedures and most physiological measurements were performed in normal artificial sea water (ASW), consisting of (in $\mathrm{mM}$ ) $460 \mathrm{NaCl}, 10 \mathrm{KCl}, 10 \mathrm{~N}$-2-hydroxyethylpiperazine- $N^{\prime}-2$ ethanesulfonic acid (HEPES), 10 glucose, $55 \mathrm{MgCl}_{2}$, and 10 $\mathrm{CaCl}_{2}, \mathrm{pH}$ 7.6. The excitability of neurons can be modulated by varying the concentration of either $\mathrm{Ca}^{2+}$ or $\mathrm{Mg}^{2+}$ in the external media (Frankenhaeuser and Hodgkin 1957). We chose not to lower $\left[\mathrm{Ca}^{2+}\right]$ below $6 \mathrm{mM}$ in our experiments, so that synaptic transmission would not be noticeably modulated or impaired. Thus the tonic activity of the neurons, in some experiments, was titrated by perfusing the cells with an ASW that had a reduced concentration of divalent ions. The solution consisted of (in mM) $550 \mathrm{NaCl}, 10 \mathrm{KCl}, 10 \mathrm{HEPES}, 10$ glucose, $0.5 \mathrm{MgCl}_{2}$, and 6 $\mathrm{CaCl}_{2}, \mathrm{pH}$ 7.6.

\section{Electrophysiology}

Standard current-clamp methods were used. Cellular properties were studied by impaling the neurons with two microelectrodes filled with $3 \mathrm{M} \mathrm{KCl}\left(R_{\mathrm{E}} \simeq 20 \mathrm{M} \Omega\right)$. Synaptic properties were studied by impaling each of a pair of neurons with two microelectrodes, one to inject current and the other to monitor voltage changes. Electrotonic coupling between neurons was measured as previously described (Bennett 1977). At least one neuron in each ensemble was penetrated with an electrode before the optical measurements. This permitted us to stimulate selected cells and provided an independent measure of cell viability over the course of the experiment.

\section{Optical recording}

Optical experiments were performed at room temperature 3 to 7 days after plating. The optical system utilized an inverted microscope and an array of 124 photodetectors (Fig. 1). The intensity and spectral bandwidth of the light were controlled with neutral density filters and narrow band interference filters, respectively. The arrangement of the optical system allowed us to measure activity-dependent changes in the optical absorption of the neurons and also allowed concurrent intracellular recordings to be made in one or two neurons. We either stored 1-s records containing the output of all of the photodetectors and the electrodes, or we stored the summed outputs from sets of six adjacent photodetectors with an FM recorder.

The neurons were vitally stained for $10 \mathrm{~min}$ with a 0.1 - to 0.2 $\mathrm{mg} / \mathrm{ml}$ solution of the potentiometric dye RH155 (Grinvald et al. 1980) (inset, Fig. 2) in ASW. The cells were subsequently washed for $15 \mathrm{~min}$ with a $0.01-\mathrm{mg} / \mathrm{ml}$ solution of the dye to reduce the concentration of unbound dye in the recording chamber. We maintained this dilute concentration of free dye throughout the measurements as a means of counteracting photobleaching of membrane-bound dye during prolonged illumination.

\section{Intracellular dye fills}

Neurons were simultaneously impaled with two microelectrodes, one to inject the fluorescent dye and the other to monitor the membrane potential. The tips of the injection electrodes were filled by capillary action with a solution of the dye: either $4 \%$ (wt/vol) Lucifer yellow (L-453, Molecular Probes, Eugene, OR) in $100 \mathrm{mM}$ ethylene glycol-bis( $\beta$-aminoethyl ether)- $N, N, N^{\prime}, N^{\prime}$-tetraacetic acid (EGTA), $10 \mathrm{mM}$ HEPES, and $2 \mathrm{mM} \mathrm{LiCl}, \mathrm{pH} 7.6$, or $2 \%(\mathrm{w} / \mathrm{v})$ sulforhodamine 101 (S-359, Molecular Probes) in $1 \mathrm{M}$ 


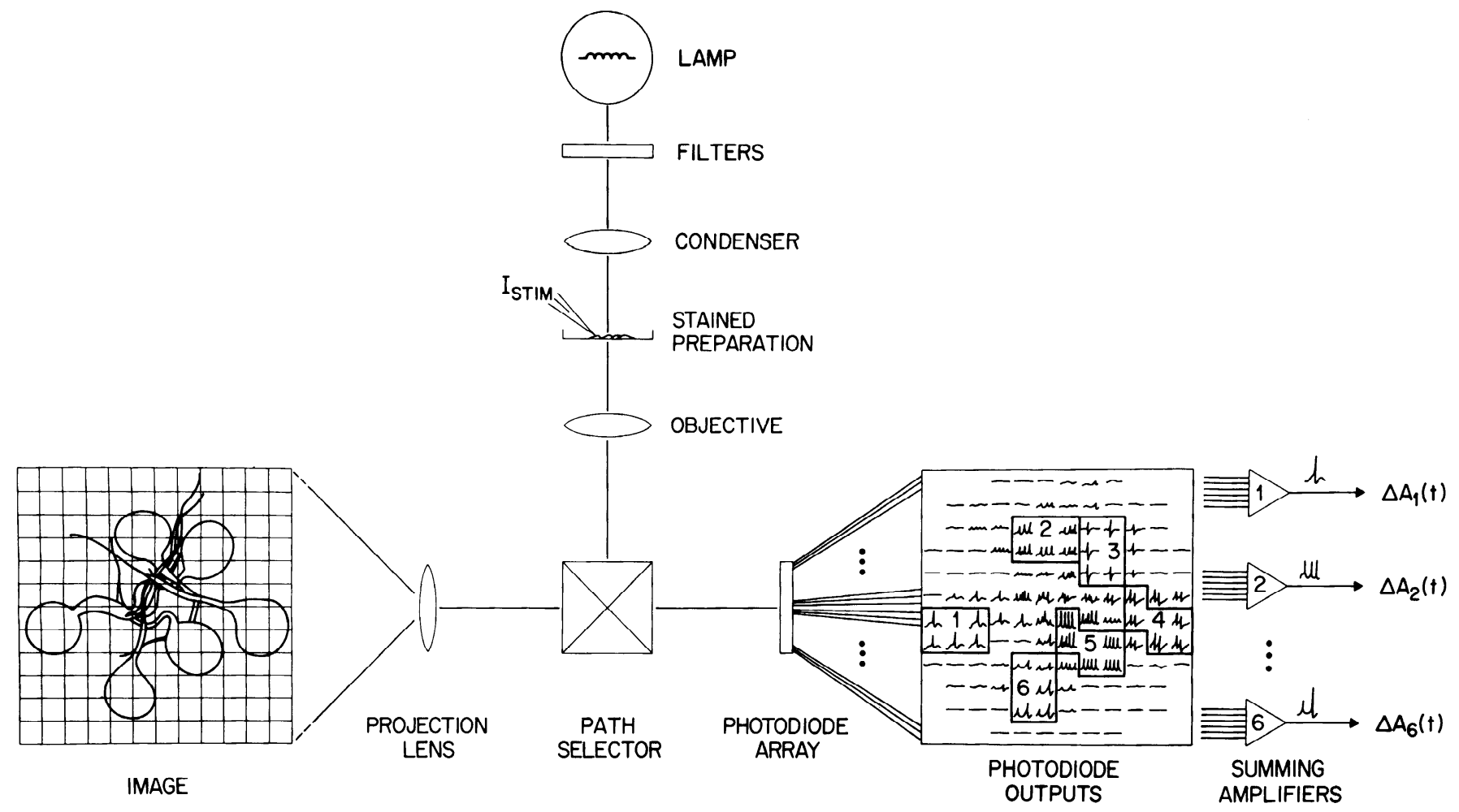

FIG. 1. Schematic drawing of the optical recording system, built around an inverted microscope to allow simultaneous intracellular and optical recording from cells in culture. Light from a tungsten-halogen lamp was collimated; the bandwidth was limited by a heat-absorbing filter and an interference filter, and the intensity was limited by neutral density filters. Light was focused onto the preparation by the use of Koehler illumination. Transmitted light was collected with a $25 \times, 0.8-\mathrm{NA}$ objective and either projected onto a $12 \times 12$ array of silicon photodiodes located at an image plane or projected through an eyepiece for viewing and photography. The field of each photodiode collected light from a $50 \times 50-\mu \mathrm{m}$ area. Currents generated by the individual photodiodes were amplified by AC-coupled current-to-voltage converters. Outputs were either digitized and stored as 1-s records or selected detector signals were summed and stored as continuous analog records.

$\mathrm{KCl}$. The shanks of the electrodes were back-filled with the respective buffer. Hyperpolarizing current pulses (4-8 nA, 50\% duty cycle at $1 \mathrm{~Hz}$ for $2 \mathrm{~h}$ ) were used to iontophorese Lucifer yellow into a cell. Pressure pulses ( $50 \%$ duty cycle at $1 \mathrm{~Hz}$ for $2 \mathrm{~h}$ ) were used to inject a cell with the sulforhodamine. Photomicrographs were taken with an inverted microscope equipped for epifluorescence. Phase-contrast photomicrographs of the same field were obtained before and after the fluorescence photomicrographs were taken.

\section{Analysis}

The temporal firing patterns of the active neurons in each ensemble were determined from the optical records (London et al. 1987). Neurons were active as a result of either tonic firing, stimulation by the injection of pulses, or stimulation via synaptic excitation. Typically, some of the neurons in an ensemble were inactive.

We interpreted the temporal firing observed for each experimental condition in terms of a set of functional connections between the neurons (Aertsen et al. 1989). This method of analysis uses the correlation in activity between different, active neurons to infer their functional connection. It is particularly useful for understanding how the firing patterns produced by neuronal circuits are shaped by their cellular and synaptic properties (e.g., Ts'o et al. 1986.)

Neurons that were quiescent but that spiked after a neighboring cell was stimulated were assigned excitatory functional inputs. In contrast, tonically active neurons with a firing rate that transiently decreased after a neighboring cell was stimulated were assigned inhibitory functional inputs. Tonically active neurons with a firing rate that decreased after the termination of a brief depolarizing intracellular current-pulse were assigned an autoinhibitory functional connection.

\section{RESULTS}

\section{Characterization of cellular and synaptic response of $L U Q$ cells in vitro}

SPIKING PROPERTIES OF LUQ CELLS. LUQ neurons modulate renal function in Aplysia (Koester and Alevizos 1989). These cells are believed to produce a rhythmic bursting output in vivo (Kramer and Zucker 1985; Scholtz et al. 1988). In contrast, previous studies found that these cells do not produce rhythmic bursts in vitro (Camardo et al. 1983; Kleinfeld et al. 1990c; but see Obaid et al. 1989). We reexamined this issue, given the importance of having a clear understanding of the spiking properties of LUQ neurons for interpreting the neuronal firing patterns produced by cells in the ensembles.

We studied the firing properties of LUQ neurons in three different culture environments, i.e., isolated LUQ neurons ( $n=20)$, co-cultured pairs of neurons (55 pairs; $n=110$ ), and ensembles of four to six neurons (30 ensembles; $n=$ 45). The firing properties were found to be independent of the environment. We observed the following. 1) All of the neurons were quiescent in the absence of external stimulation when bathed in normal ASW (Fig. 2A). 2) The cells 


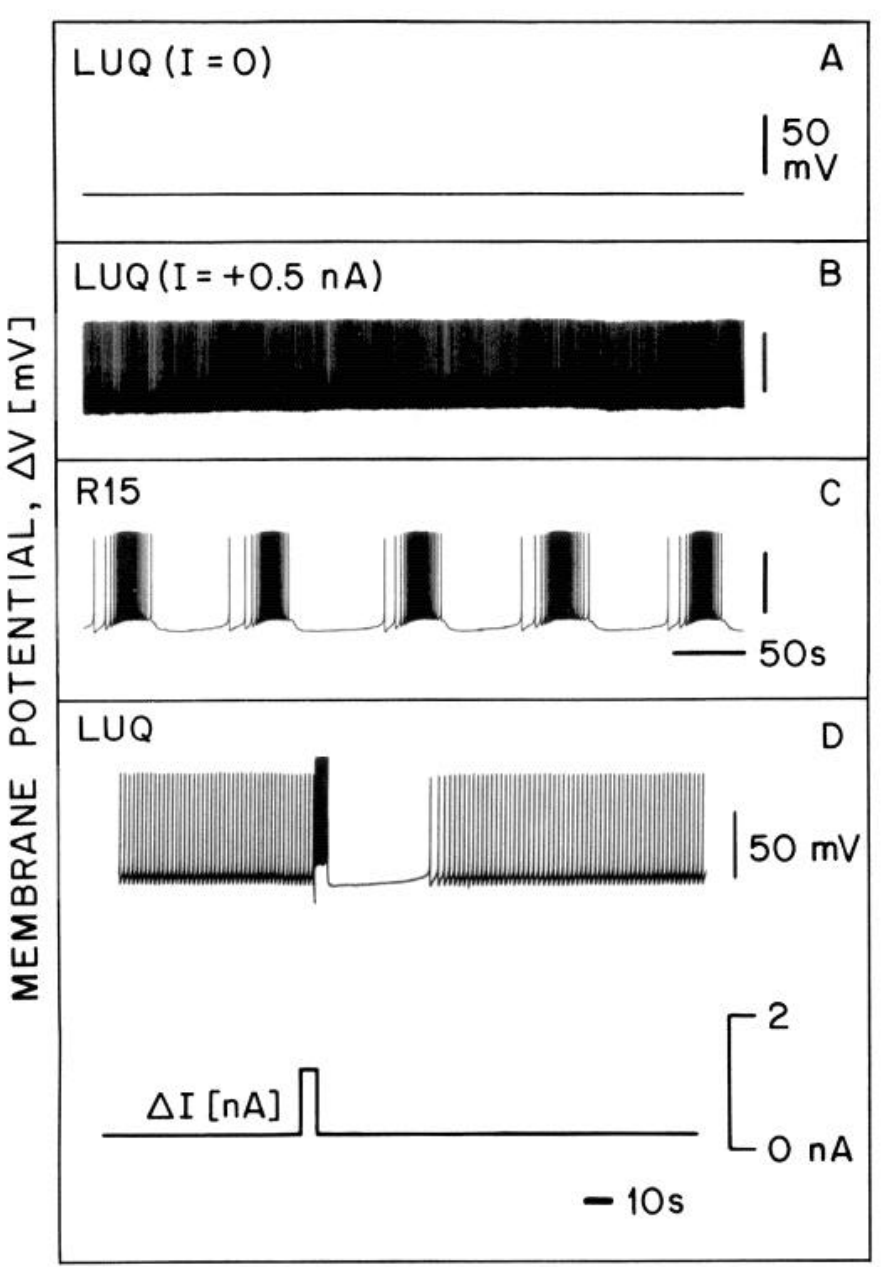

TIME

FIG. 2. The firing properties of an isolated LUQ neuron in vitro. $A$ : output from an LUQ neuron with no external intracellular current. This cell stayed near its resting potential, $-52 \mathrm{mV}$, and did not produce bursts of action potentials over a period of $2 \mathrm{~h}$. It is typical of the cells used in this study. $B$ : output from the same LUQ neuron after it was depolarized by the injection of $0.5 \mathrm{nA}$. This cell fired tonically at a rate of $\sim 0.8 \mathrm{spikes} / \mathrm{s}$ for $\geq 30 \mathrm{~min}$. $C$ : output from a cultured R15 neuron. This cell produced wellcharacterized bursts of action potentials, with no external input, that were characteristic of its in vivo bursting properties (see text). These data suggest that our culture procedures do not interfere with the intrinsic firing properties of the cultured Aplysia neurons. D: postburst hyperpolarization in a cultured LUQ neuron. Cell was tonically activated over the course of the experiment by the continuous injection of $0.3 \mathrm{nA}$. Brief bursts of activity were elicited by an additional $1.0-n A$ pulse of current. Note that a transient quiescent period follows the termination of the burst of activity.

could be induced to fire tonically by the constant injection of small, depolarizing currents (Fig. $2 B$ ). A current of $\sim 0.5$ nA was typically needed to drive a cell just above its threshold for firing. Cells typically fired at $0.3-1$ spike/s near threshold, and the tonic output persisted for $\geq 20 \mathrm{~min}$. This period was longer than the period of the stimulus paradigm with the ensembles. 3) No LUQ cell produced a rhythmic bursting output under any of our experimental conditions. ${ }^{1}$

\footnotetext{
${ }^{1}$ Although none of the LUQ neurons produced rhythmic bursting under the conditions used in the present study, LUQ neurons may produce a bursting output in vitro under other experimental conditions (Obaid et al. 1989).
}

The firing properties of the neurons could, in principle, be altered by the isolation and culture procedures. Thus we checked our techniques by examining the firing properties of cultured R15 cells. This cell produces a stereotyped output, consisting of bursts of action potentials that are separated by periods of hyperpolarization (Adams and Benson 1985; Strumwasser 1965). The bursting properties are readily lost from damage and manipulations (Kramer et al. 1988; Meech 1979).

The output from a cultured R15 cell is shown in Fig. $2 C$. Note the regularity of the burst frequency and the stereotypical pattern of spiking within each burst. These features correspond closely with the behavior reported for R15 in vivo (Strumwasser 1965). Similar results were found with other cultures of R 15 cells $(n=5)$. These results suggest that our culture techniques do not markedly alter the intrinsic properties of neurons.

POSTBURST HYPERPOLARIZATION IN LUQ CELLS. In our analysis of the behavior of neuronal ensembles, we stimulated individual neurons with strong pulses of intracellular current. The pulses were typically $5 \mathrm{~s}$ in duration and caused a neuron to fire at $\sim 5-10$ spikes/s. This firing rate was much greater than the rate at which neurons fired tonically in ASW with reduced concentrations of $\mathrm{Mg}^{2+}$ (compare Figs. 8 and 10). Thus we examined the firing properties of LUQ cells after strong, transient excitation.

Individual LUQ neurons $(n=30)$ were maintained at a low firing rate $(\sim 1$ spike/s) through the intracellular injection of current. An additional depolarizing current-pulse was briefly superimposed and caused the neurons to fire transiently at a high rate, $\sim 10$ spikes/s. At the termination of the pulse we observed that the neurons stopped firing rather than return to their initial low rate of activity (Fig. $2 D$ ). The postburst hyperpolarization typically lasted for $\sim 40 \mathrm{~s}$.

SYNAPTIC INTERACTIONS BETWEEN LUQ NEURONS. Two forms of synaptic interactions were found in the present study. The most prevalent interaction was a slow, inhibitory response (Fig. $3 A$ ). A hyperpolarizing postsynaptic potential was observed in response to a brief burst of action potentials in the presynaptic cell. Single action potentials or firing rates less than $\sim 0.3 \mathrm{spike} / \mathrm{s}$ in the presynaptic cell did not elicit a postsynaptic response. The hyperpolarization had an onset time of $\sim 1 \mathrm{~s}$ and decayed with biphasic kinetics. The decay time of the faster phase was $\sim 10 \mathrm{~s}$, whereas that of the slower phase was substantially longer (Fig. $3 A$ ). The synaptic response could be canceled, but not reversed, after the injection of hyperpolarizing current into the postsynaptic cell.

We also observed a novel dual-action postsynaptic response between co-cultured LUQ cells (Fig. 3B). An inhibitory response was followed by delayed excitation. The hyperpolarization had an onset time that was similar to that for the solely inhibitory response (cf. Fig. 3, $A$ and $B$ ). The onset of excitation was delayed by 5-10 s from the burst of spikes in the presynaptic cell.

The delayed excitation of the dual-action response could arise directly from a synaptic mechanism or secondarily from the activation of an intrinsic, depolarizing cellular current. The latter possibility occurs in many invertebrate 


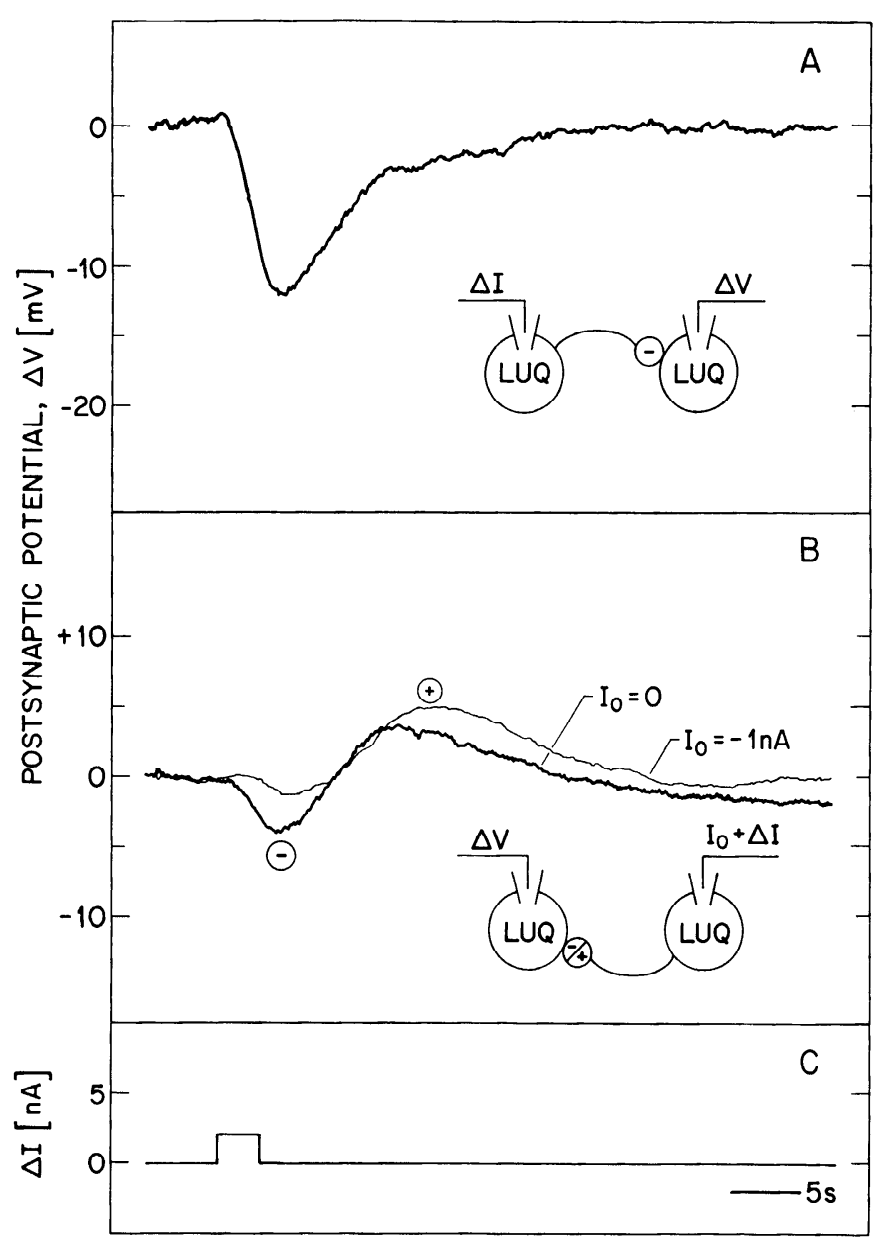

TIME

FIG. 3. Synaptic interactions between pairs of co-cultured LUQ neurons. Change in intracellular potential, $\Delta V$, was recorded from the postsynaptic cell in response to a burst of $\sim 20$ action potentials in the presynaptic cell. Burst was elicited by a $2-$ s pulse of intracellular current, $\Delta I$. $A$ : a solely inhibitory postsynaptic response between LUQ cells. This was the most common response (see text). $B$ : a dual-action postsynaptic response, with inhibition followed by excitation (thick line). Thin line shows the response when the postsynaptic cell was hyperpolarized via the injection of $-1 \mathrm{nA}$. Note that the inhibitory response is nulled, whereas the excitatory response persists, implying that the excitation is not the result of postinhibitory rebound. This response occurred in a relatively small fraction of the co-cultured cells (see text).

neurons and is referred to as postinhibitory rebound (Satterlie 1985). Two experiments were performed to distinguish between these possibilities. First, the postsynaptic response was observed while hyperpolarizing current was injected into the postsynaptic cell. We found that excitation was accentuated, although the magnitude of the inhibitory response was reduced by the hyperpolarization, suggesting that the excitation arises from a synaptic mechanism that does not depend on the preceding inhibition.

In a second set of experiments, we observed the response of individual LUQ neurons after the injection of a hyperpolarizing current-pulse. The duration of the pulse was varied between 5 and $15 \mathrm{~s}$ and its magnitude was adjusted to give a potential change of approximately $-10 \mathrm{mV}$; these values are close to the characteristics of the inhibitory synaptic response (Fig. 3). Essentially no depolarization occurred after the termination of a pulse (data not shown). This suggests that the excitation is not the result of an intrinsic cellular mechanism. ${ }^{2}$

Solely inhibitory connections occurred in $35 \%$ of the cocultured LUQ pairs we examined ( $n=55$; each pair used cells from the same animal). Reciprocal inhibitory connections occurred in $12 \%$ of the pairs. Only a small fraction of dual-action connections occurred in the co-cultured neurons, $\sim 10 \%$. However, the fraction of such connections was greater, $\sim 20 \%$, in ensembles that contained four or more neurons, as opposed to two neurons. The reasons for this enhancement are unclear. Last, many of the cultured cells formed relatively weak electrical connections $(k=0.1-$ 0.2 ) in addition to chemical connections.

\section{Long-term optical recording}

OPTIMAL INCIDENT WAVELENGTH. Previous work has shown that the potentiometric probe RH155 is bound by Aplysia cells both in vivo (Zecevic et al. 1989) and in vitro (Parsons et al. 1989a). These studies were concerned with the general feasibility of using optical methods to observe electrical activity in Aplysia neurons. They showed that the change in absorption of the dye accurately followed the change in membrane potential. However, the dependence of the absorption change on the wavelength of the incident light was not quantified for this preparation. This quantification is critical for the choice of optimal wavelength and spectral bandwidth.

The change in optical absorption for a neuron stained with the dye RH155 is shown as a function of wavelength in Fig. 4. An isolated LUQ neuron was stained and subsequently impaled with a microelectrode. A single photodetector in the array collected light from the initial segment of the neuron. We injected brief pulses of current into the cell and recorded the changes in optical absorption that occurred at the peak of the action potential. The spectral bandwidth at each wavelength was $10 \mathrm{~nm}$. The absorption changes in the cell were normalized by the change in the cell membrane potential. The essential results were (Fig. $4 A$ ) as follows. 1) The absorption change was biphasic. 2) The largest absorption change occurred at $700 \mathrm{~nm}$, with a bandwidth of $\sim 40 \mathrm{~nm}$ (full width at half maximum). The magnitude of this change was typically $\Delta A / \Delta V \simeq 6 \times 10^{-6}$ per $\mathrm{mV}$, approximately $\Delta A \simeq 4 \times 10^{-4}$ per spike. 3) The magnitude of the maximum response varied within a range that included a factor of $\sim 3$ among different Aplysia cells $(n=$ $50)$ in this spectral range.

MINIMUM LIGHT INTENSITY. The intensity of the incident illumination affects the measurement in two ways: 1 ) the signal-to-noise ratio of the change in absorption measured by each detector is a function of the intensity; and 2) removal of dye by photobleaching and the generation of toxic reactive products of the dye molecules' excited state (phototoxicity), both of which depend on the intensity of the illumination, limit the recording time.

\footnotetext{
${ }^{2}$ We assume that the effects of electrotonic attenuation between the soma and the processes are small, as has been demonstrated for other Aplysia neurons in culture (Spira et al. 1988).
} 

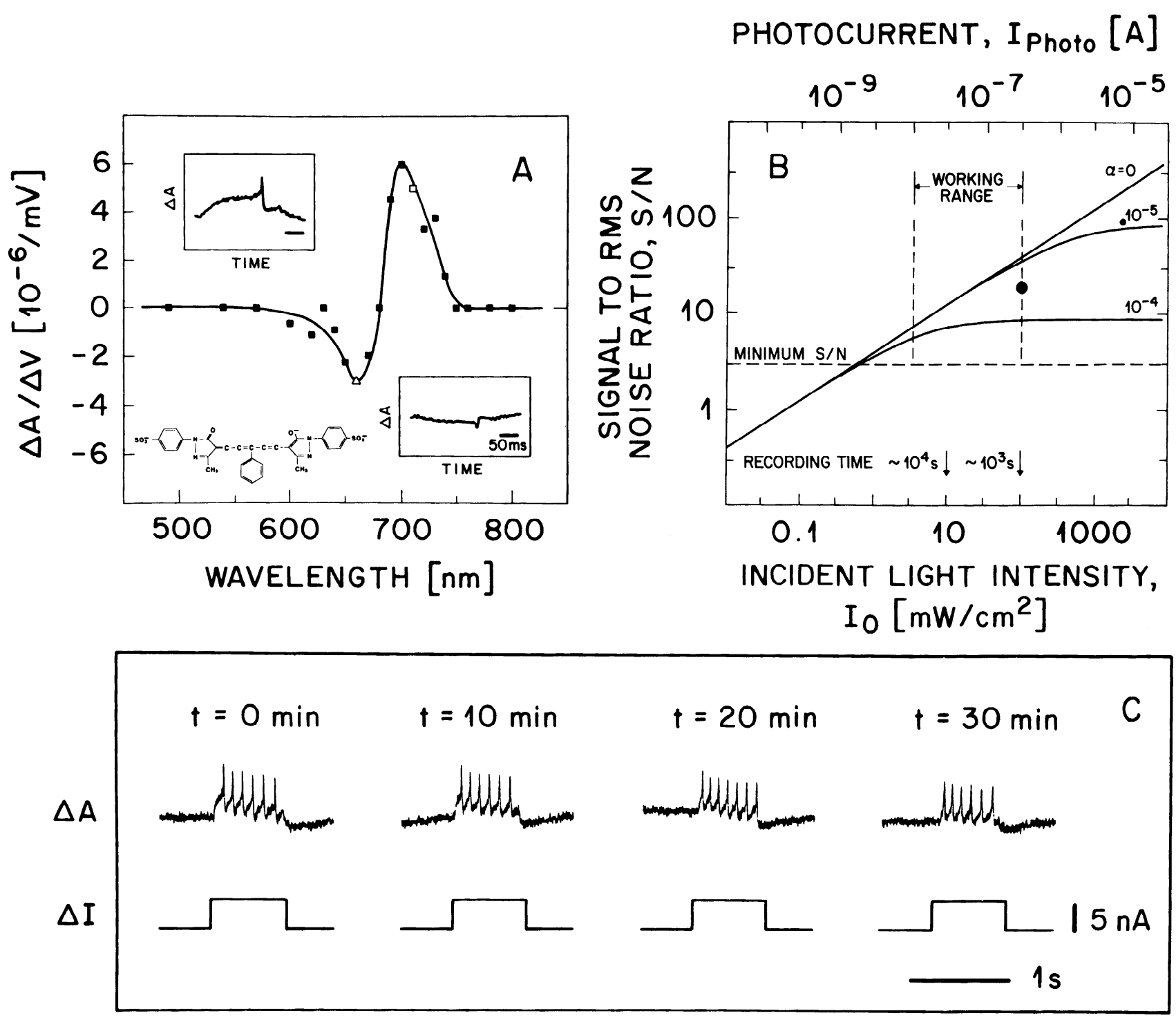

TIME

FIG. 4. Optimal conditions for long-tcrm optical recording. $A$ : wavelength dependence of the optical absorption change of membrane stained with the dye RH155 that accompanied an action potential in cultured Aplysia neurons. An isolated LUQ cell was vitally stained (METHODS) with RH155 at a concentration of $0.1 \mathrm{mg} / \mathrm{ml}$. Changes in the absorption were measured by exciting the cell with a brief pulse of current through an intracellular electrode. Inset, top left: optical signal recorded by a single photodetector during illumination at $710 \mathrm{~nm}(\square)$. Inset, bottom right: signal observed for illumination at $660 \mathrm{~nm}(\triangle)$. Inset, bottom left: chemical structure of RH155. B: the calculated S/N ratio for observing an action potential from a typical neuron, with $\Delta A=4 \times 10^{-4}$. Top curve, with $\alpha=0$, corresponds to the shot noise limit. Other curves correspond to cases in which the $\mathrm{S} / \mathrm{N}$ ratio is limited by technical noise $\left(\alpha=I_{\text {Tech }} / I_{\text {Photo }} \neq 0\right)$. A S/N ratio of $\sim 3$ is required to detect an action potential in a single sweep. Dot corresponds to the data shown in $C$. $C$ : long-term continuous optical recording from a cultured LUQ neuron. Intensity of the incident light was $I_{0} \sim 100 \mathrm{~mW} / \mathrm{cm}^{2}$ throughout the $30 \mathrm{~min}$ shown. Output from a single photodetector is shown at 10-min intervals; action potentials were elicited by a current-pulse through an intracellular electrode. Note that there was essentially no deterioration of the optical signal over the course of this experiment.

The signal is the change in absorption that accompanies a spike. It depends on the absorption change, $\Delta A$, the incident light intensity, $\mathbf{I}_{0}$, and the area of cell membrane within the field of each photodetector. For the relevant case of small changes in absorption, the signal current, $\Delta I_{\text {Photo }}$, is given by $\Delta I_{\text {Photo }}=2.3 \cdot \Delta A \cdot I_{\text {Photo }}$. The steady-state photocurrent, $I_{\text {Photo }}$, is related to the incident light intensity by $I_{\text {Photo }}=R \cdot \mathbf{I}_{0}$, with the responsivity, $R$, determined to be $R \simeq 4 \times 10^{-9} \mathrm{~A} \cdot \mathrm{mW}^{-1} \cdot \mathrm{cm}^{-2}$ for the field of view of each photodetector in our system (Fig. 1).
There are many sources of noise that may contribute to optical measurements of membrane potential (e.g., Cohen and Lesher 1986; Salzberg et al. 1977). In our experiments the dominant noise source at low intensities of illumination was the statistical fluctuation in the intensity of the light, i.e., shot noise. The dominant source of noise at high intensities was technical noise, resulting from changes in absorption that occurred secondary to vibrations of the lamp and the preparation. The shot current, $I_{\text {Shot }}$, is given by $I_{\text {Shot }}=$ $\sqrt{4 \cdot e \cdot I_{\mathrm{Photo}} \cdot \Delta v}$, where $e$ is the electronic charge and $\Delta v$ is 

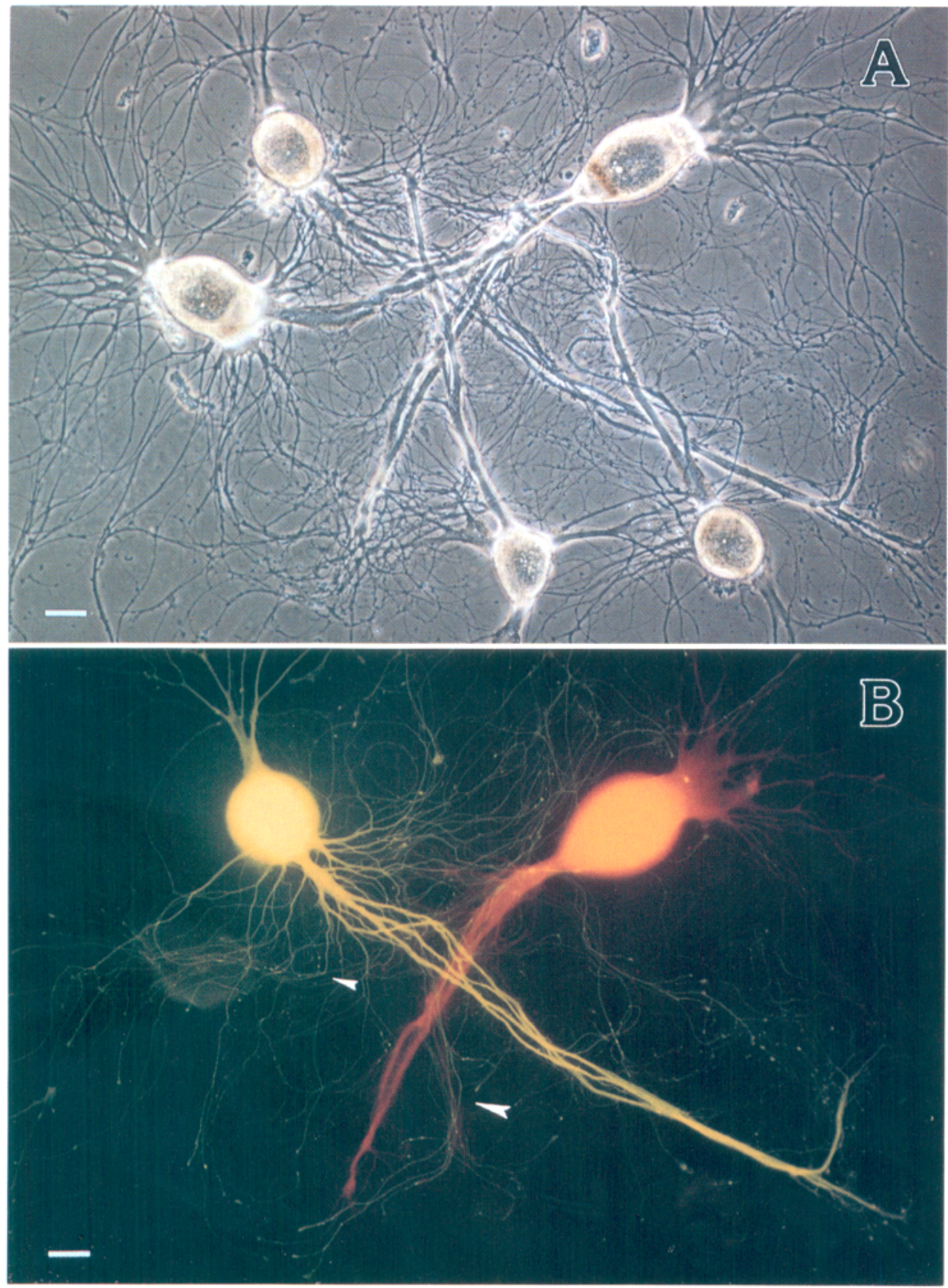

FIG. 5. Illustration of the extensive overlap of neurite outgrowth in an ensemble of co-cultured neurons. $A$ : phase-contrast photomicrograph. The 5 somata and their initial segments, as well as a plethora of regenerated fine processes, are seen. $B$ : photomicrograph of fluorescently labeled neurons that illustrates the true extent and course of neurite outgrowth. Processes from the 2 cells, one injected with Lucifer yellow and the other with sulforhodamine, are observed to overlap extensively with each other (e.g., larger arrow) and with unlabeled cells (e.g., smaller arrow). Scale bar, $100 \mu \mathrm{m}$. the amplifier bandwidth; $\Delta v \simeq 300 \mathrm{~Hz}$ for our system. ${ }^{3}$ The technical noise current, $I_{\text {Tech }}$, can be expressed as $I_{\text {Tech }}=$ $\alpha(v) I_{\text {Photo }}$, where the factor $\alpha(v)$ depends on the physical characteristics of the system. We found that $\alpha(v)$ could be approximated as a constant that lies in the range $10^{-5}<$ $\alpha<10^{-4}$.

Consideration of the signal-to-noise ratio allows the minimum value of $\mathbf{I}_{0}$ to be calculated. The ratio of the signal to the root mean square value of the noise $(\mathrm{S} / \mathrm{N})$ is

$$
\frac{\mathrm{S}}{\mathrm{N}}=\frac{\Delta I_{\text {Photo }}}{\sqrt{I_{\text {Shot }}^{2}+I_{\text {Tech }}^{2}}}=2.3 \Delta A \sqrt{\frac{R \mathbf{I}_{0}}{4 e \Delta v+\alpha^{2} \cdot R \cdot \mathbf{I}_{0}}}
$$

${ }^{3}$ More generally, the shot noise is given by $I_{\text {Shot }}=\sqrt{2(1+\sigma) e \cdot I_{\text {photo }} \cdot \Delta v}$, where $\sigma=1$ for an incoherent source, such as a filament lamp, and $\sigma=0$ for a coherent source, such as a laser (Kingston 1978).
A plot of the $\mathrm{S} / \mathrm{N}$ ratio as a function of $\mathrm{I}_{0}$ and $\alpha$, for $\Delta A=$ $4 \times 10^{-4}$, is shown in Fig. $4 B$. The $\mathrm{S} / \mathrm{N}$ ratio increases with increasing intensity until it reaches an asymptotic value of $\mathrm{S} / \mathrm{N}=2.3(\Delta A / \alpha)$.

The signal-to-noise ratio must be $\mathrm{S} / \mathrm{N} \sim 3$ to observe a spike reliably in a single optical record (e.g., Motchenbacher and Fitchen 1973). For a single photodetector, this implies a minimum intensity of $\mathbf{I}_{0} \sim 1 \mathrm{~mW} / \mathrm{cm}^{2}$ (Fig. $4 B$ ). Higher intensities may be required, both to compensate for weakly stained cells and to facilitate the analysis of the optical signal when many neurons are simultaneously active in the field of a detector (next section). In practice, this suggests that typical light intensities must be $\mathbf{I}_{0} \geq 3 \mathrm{~mW} / \mathrm{cm}^{2}$. LONG-TERM RECORDING. We examined the long-term viability of cultured Aplysia cells under continuous illumination in the range $\mathbf{I}_{0} \sim 3-100 \mathrm{~mW} / \mathrm{cm}^{2}$ with $\lambda=700 \pm 5$ 
means FWHM $=10 \mathrm{~nm}$. A typical example of the output observed with a single photodetector, using the relatively high intensity of $\mathbf{I}_{0}=100 \mathrm{~mW} / \mathrm{cm}^{2}$, is shown in Fig. $4 C$. The cell was illuminated continuously, and the optical signal was probed at 5 -min intervals by injecting a brief pulse of depolarizing current. We observed a $S / N \sim 20$, which is close to the theoretical limit (dot in Fig. 4B). There was essentially no deterioration of the optical signal, either from photobleaching or photodynamic damage, over a period of $20 \mathrm{~min}\left(\sim 10^{3} \mathrm{~s}\right)$ and only slight photobleaching of the preparation after $30 \mathrm{~min}$ (Fig. $4 C$ ).

We were able to record for several hours $\left(\sim 10^{4} \mathrm{~s}\right)$ with light intensities of $\mathbf{I}_{0} \sim 3 \mathrm{~mW} / \mathrm{cm}^{2}$. In our best preparations we achieved an apparent shot noise limited signal-to-noise ratio of $S / N=3-10$; the precise value of the $S / N$ ratio was dependent on the staining characteristics of the neurons. In the worst cases, in which the preparation was weakly stained or the technical noise was unusually high, the signal-to-noise ratio for each photodetector was $<3$ at these intensities. Enhancement of the signal-to-noise ratio was obtained by summing the outputs (spatial averaging) of photodetectors with fields that encompassed the same neuron (Fig. 1). Summing the outputs of adjacent photodetectors was often effective in canceling technical noise that originated from a cell vibrating across the boundary of two detector fields.

\section{Determination of functional connectivity.}

ENSEMBLES OF LUQ NEURONS. We recorded optically the patterns of electrical activity that were generated by ensembles consisting of four to six LUQ cells $(n=30)$. First, the temporal firing patterns of individual neurons within the ensemble were determined, and then this information was used to infer the functional connectivity between the neurons of the ensemble. The tonic activity of the neurons was incrcased by using ASW with reduced concentrations of $\mathrm{Mg}^{2+}$.

SPATIAL DISTRIBUTION OF THE OPTICAL SIGNAL. Cultured Aplysia neurons are capable of exuberant regeneration of neurite processes in vitro (Schacher and Proshansky 1983). This leads to extensive overlapping of the processes of individual neurons with those of other cells, because individual neurons must be placed in close proximity to each other to facilitate synaptic interactions (Camardo et al. 1983; Kleinfeld et al. 1990b).

We illustrate the overlapping nature of the cellular outgrowth from an ensemble of five LUQ neurons with phase contrast microscopy in Fig. $5 \mathrm{~A}$. Details of the extent of overlap between the processes of individual neurons were followed by staining two of the five cells with the fluorescent dyes Lucifer yellow and sulforhodamine, respectively. The outgrowth from each of the stained cells was observed to have a distinct pattern (Fig. $5 B$ ). Further, the processes were highly intertwined in a directed manner. The fine processes from one cell track along the processes of the other cell (larger arrow, Fig. $5 B$ ), and processes from both cells localize to the region of an unlabeled soma (smaller arrow; Fig. 5B). Qualitatively similar patterns of overlap were observed with other ensembles $(n=4)$.
Previous work has established that action potentials propagate in the fine processes of cultured Aplysia neurons (Parsons et al. 1989a) and that these processes are approximately equipotential with the cell soma (Spira et al. 1988). The overlapped outgrowth of the processes should thus cause each photodetector to record the activity of many cells. We examined this issue by recording the spatial patterns of optically detected electrical activity from individual cells in an ensemble. This is illustrated using the ensemble shown in Fig. $6 A$, in which intracellular electrodes were placed in two of the five cells ( $a$ and $b$, Fig. $6 A$ ). A pattern of electrical activity is resolved in $25 \%$ of the photodetectors after activation of cell $a$ with a current pulse (Fig. $6 B$ ). The pattern mirrored the gross morphology of the cell. A different pattern was observed after activation of cell $b$ (Fig. 6C). The spatial distribution of activity in each cell remained invariant over the recording time of $1 \mathrm{~h}$, with $\mathrm{I}_{0} \sim 10 \mathrm{~mW}$ / $\mathrm{cm}^{2}$. This indicates that the cells and their fine processes remained viable.

The differences between the two patterns of activity that were detected optically should allow one to resolve the contributions from the individual neurons when both cells are active. We examined this issue by sequentially activating cells $a$ and $b$. The summed outputs from photodetectors comprising six different non-overlapping regions (Fig. 6, $A$ and $D$ ) are shown in Fig. $6 E$. The amplitude of the optical changes observed in regions 3 and 5 are largest for the two action potentials induced in cell $a$ (cf. $\Delta A_{3}$ and $\Delta A_{5}$ with $\Delta V_{\mathrm{a}}$, Fig. $6 E$ ). The fields in these regions contain the initial segment from cell $a$ but largely exclude the segment from cell $b$. In contrast, the optical changes observed in region 1 are largest for the action potential induced in cell $b$ (cf. $\Delta A_{1}$ with $\Delta V_{\mathrm{b}}$, Fig. $6 E$ ). This region contains a portion of the initial segment of cell $b$ but none of that of cell $a$. The optical changes in other areas, such as region 4 , are roughly the same amplitude for action potentials in either cell. This region contained the initial segments of both cells.

Our results suggest that the electrical activity of individual neurons within an ensemble can be resolved with optical methods. The resolution depends on 1) the spatial distribution among different optical fields of temporally coincident events, e.g., action potentials from the same cell; and 2) differences in the amplitude of discrete temporal events, e.g., spikes from different cells, within the same optical field (Nakashima et al. 1989; Zecevic et al. 1989).

DISCRIMINATION OF INDIVIDUAL TEMPORAL FIRING PATTERNS. The derivation of single cell firing times from the optical records is critical for understanding the synaptic interactions between neurons within in vitro ensembles (Parsons et al. 1989a). We sought to use the spatial and temporal differences in the activity, discussed above, to decompose the optical signals observed from ensembles of simultaneously active cells. An ensemble of five LUQ cells is shown in Fig. $7 A$. Three cells were subsequently determined to be spontaneously active during the experiment and two cells were activated by the injection of intracellular current. The summed optical outputs from five different regions (Fig. $7 A$ ) are shown in Fig. $7 B$; a temporal expansion of the records is shown in Fig. $7 C$.

The spikes recorded from a given region of the ensemble could be classified according to their relative amplitude. 
PARSONS ET AL.
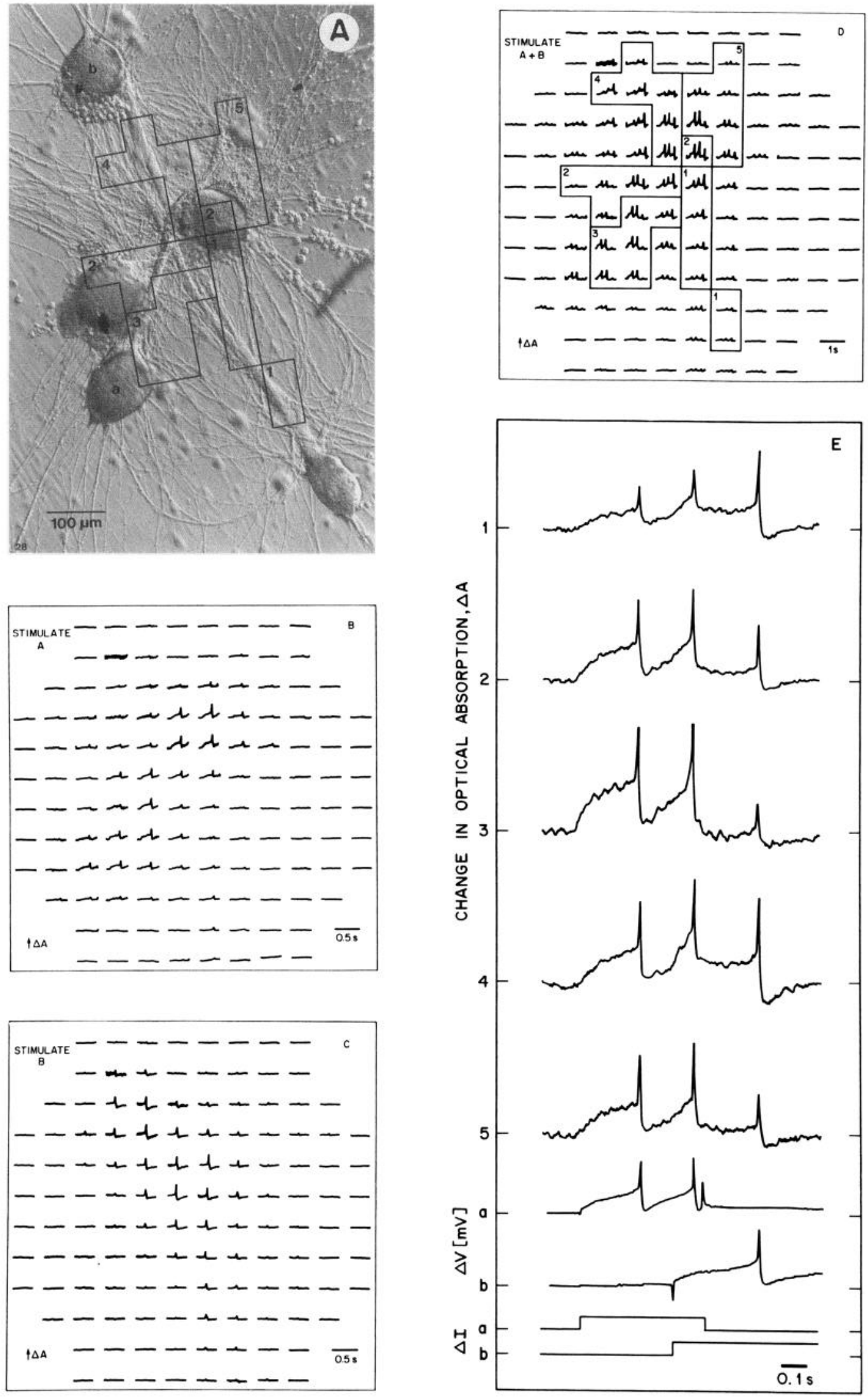

TIME 

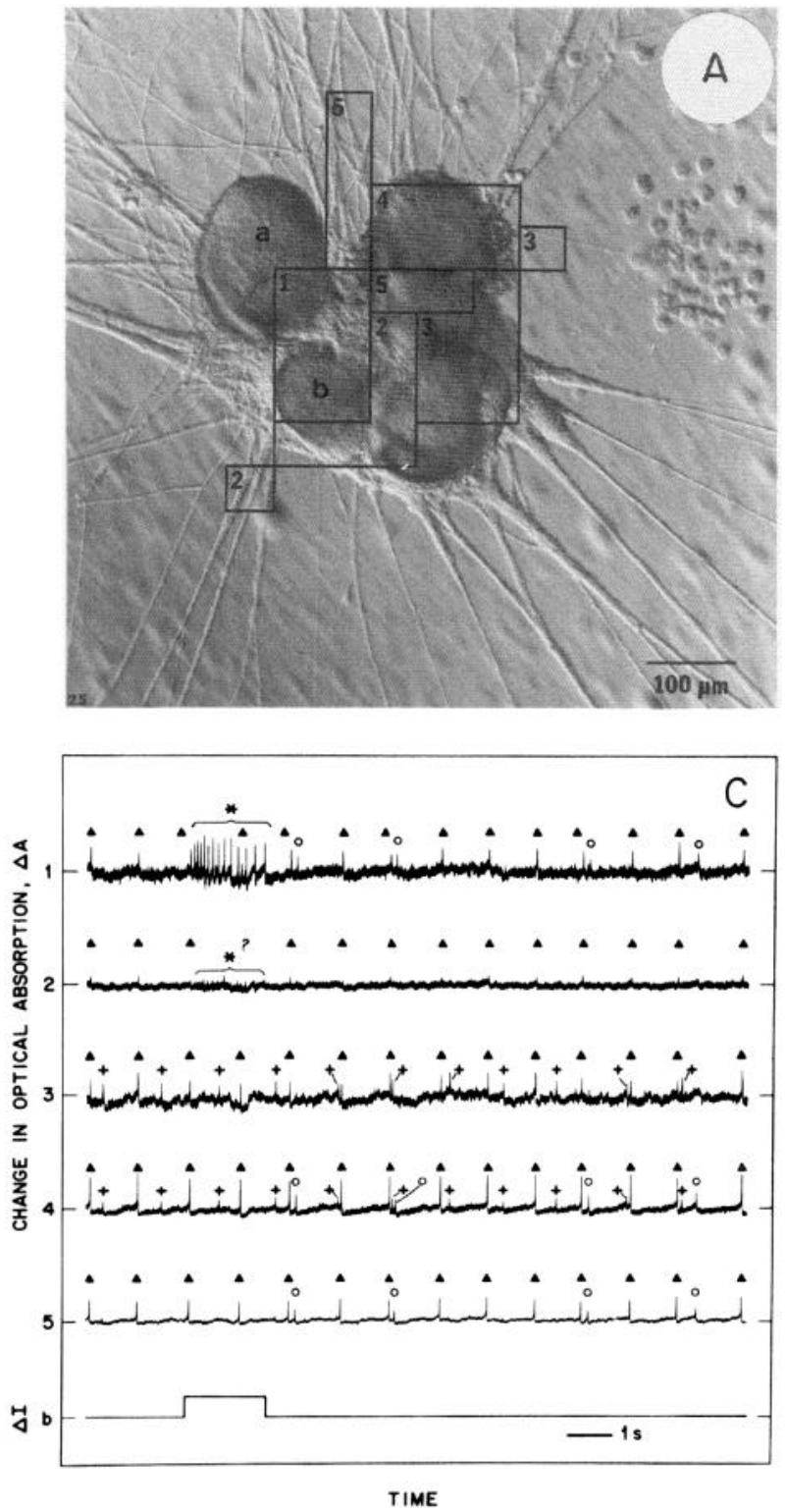

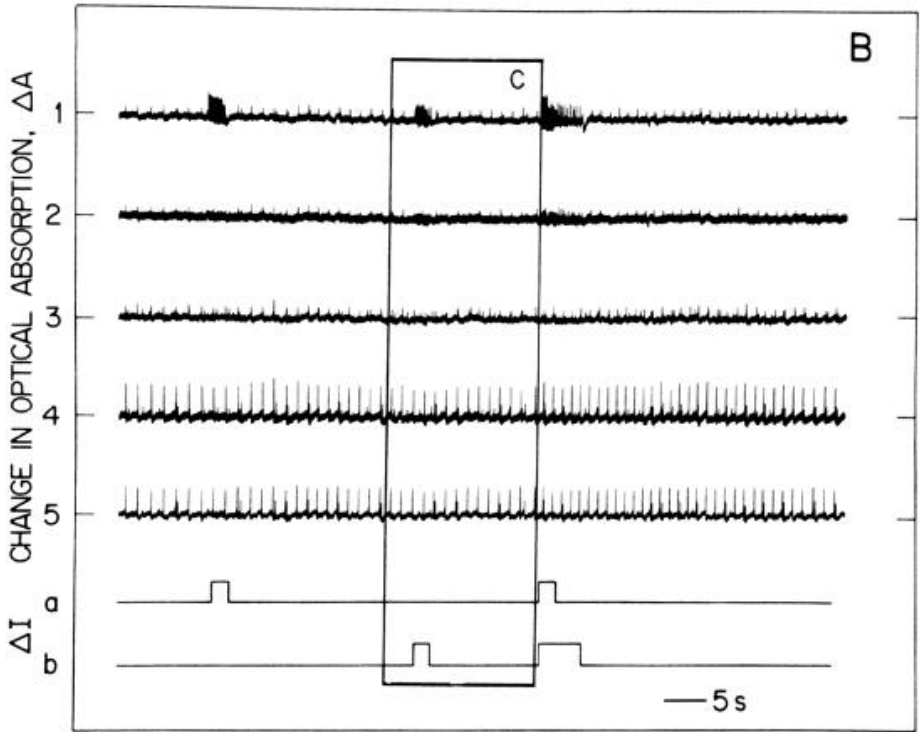

TIME

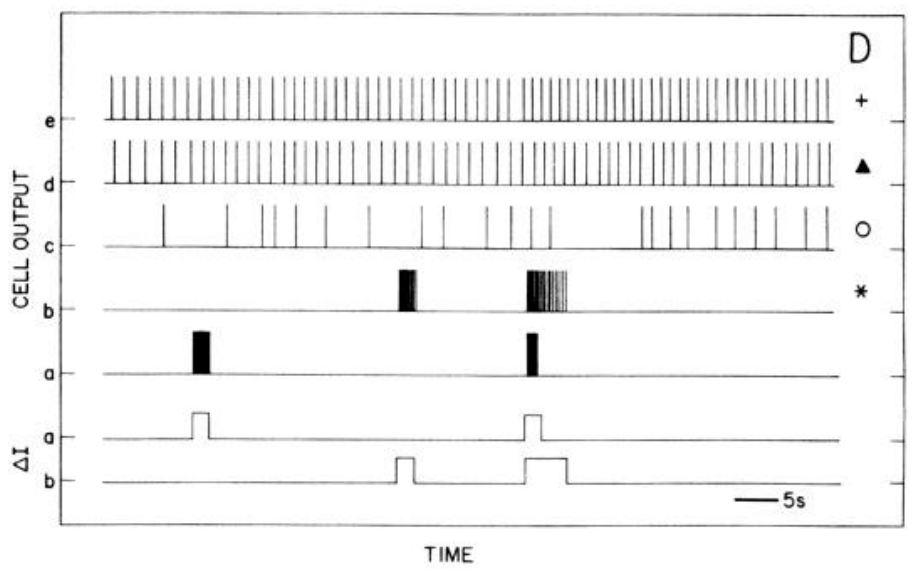

FIG. 7. Reconstruction of the individual spike trains from the optical records of an ensemble of LUQ neurons partially activated using ASW with a low concentration of divalent ions. Incident light intensity was $\sim 8 \mathrm{~mW} / \mathrm{cm}^{2}$. These data illustrate our procedure for interpreting the complex, multiple-site optical records that occur when many or all of the cells in an ensemble are active. $A$ : photomicrograph of the ensemble of 5 neurons. Outlines indicate the regions for each set of consolidated photodetector outputs. B: records of the summed detector outputs. High level of background activity was induced by bathing the cells in ASW having a low concentration of divalent ions. Spiking activity of different amplitudes and temporal patterns can be seen on all 5 records. Note that 2 of the 5 cells were stimulated with intracellular current pulses. $C$ : temporal expansion of outlined region of the records in $B$. Spikes occurring within a given record were sorted according to their relative amplitude. Those with the same amplitude in a given record, or that occurred at the same time in different records, were assigned a common symbol; record $1, O, *, \Delta$; record $2, *, \Delta ;$ record $3, \Delta,+$; record $4,0, \Delta,+;$ and record 5,0 , $\triangle . D$ : representation of the firing patterns for the 5 cells active in the optical record shown in $C$. Each of the spikes labelled with different symbols in $C$ was assumed to represent the output of an individual neuron; cell $a$ did not spike during this expanded portion of the record.

FIG. 6. Multiple-site optical recording of the electrical activity from individual cells within an ensemble. Incident light intensity was $\sim 30 \mathrm{~mW} / \mathrm{cm}^{2}$. This figure illustrates the spatial extent of signals recorded from cells with extensive, overlapping neurite outgrowth. $A$ : photomicrograph showing the exuberant neurite outgrowth of the co-cultured cells. $B$ : changes in the optical absorption, recorded by each photodetector, after the excitation of cell a with an intracellular current-pulse. Spatial distribution of the optical signals corresponds to the location of the soma and initial segment of cell $a$, although optical changes in the fine processes can be discerned. $C$ : activation of cell $b$ results in a different pattern of activity from that in cell $a$. $D$ : changes in optical absorption that are observed when cells $a$ and $b$ are activated sequentially. Complex multicellular optical signals occurred when a photodetector measured the changes from both cells. $E$ : 5 optical changes, $\Delta A_{1}$ through $\Delta A_{5}$, represent the off-line summation of the output from 6 photodetectors (each) within the regions outlined in $A$ and $D$. Voltage changes $\Delta V_{a}$ and $\Delta V_{b}$ are the intracellular records of the electrical activity in cells $a$ and $b$, respectively. Note that the relative amplitudes of the optical signals that reflect discrete events (e.g., 2 spikes in cell $a$ and 1 spike in cell $b$ ) varied among the 5 regions, whereas the timing of these signals was essentially invariant among the regions. 

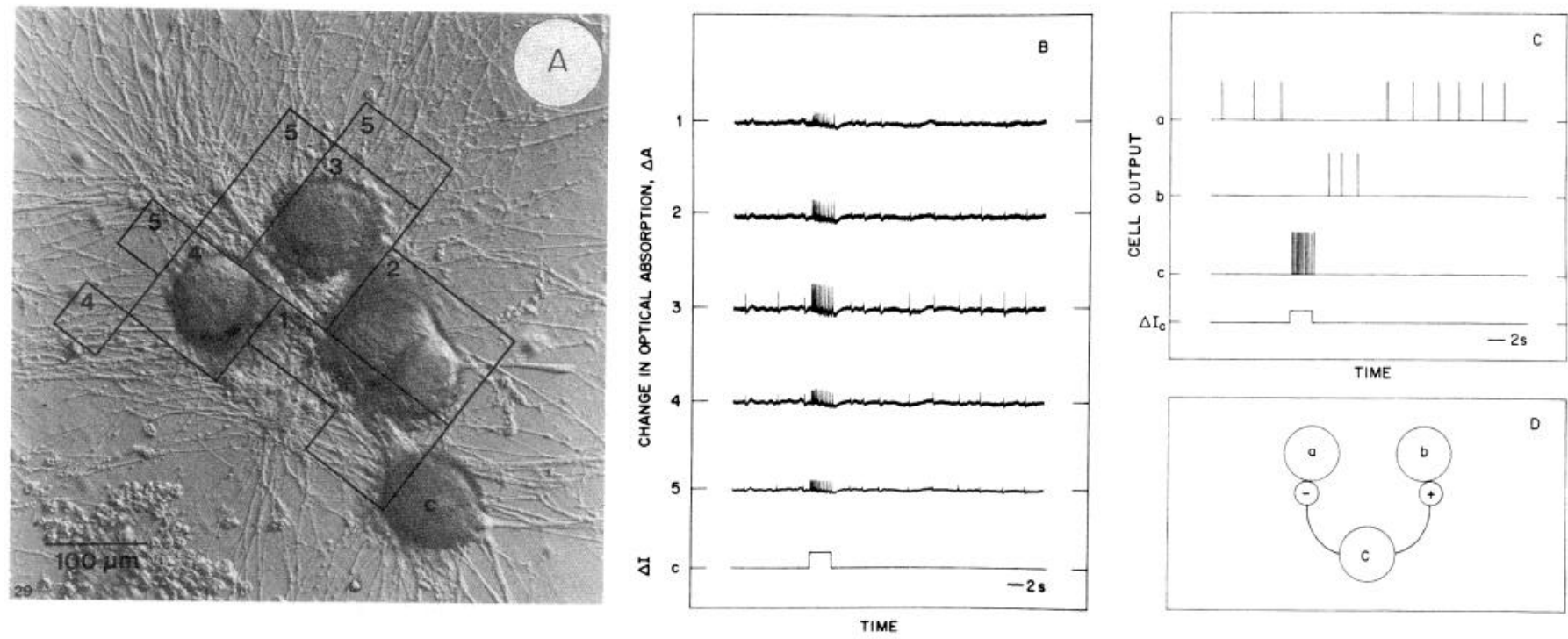

FIG. 8. Determination of functional connectivity within a neuronal ensemble. $A$ : photomicrograph of the ensemble of 5 LUQ cells. Outlined areas correspond to fields of 5 summed photodetector outputs. An intracellular electrode was placed in cell $c$ during the experiments. $B$ : multiple-site optical records for summed detector outputs. Preparation was stained with the dye RH155 and illuminated at a wavelength of $700 \pm 5 \mathrm{~nm}$ and an intensity of $15 \mathrm{~mW} / \mathrm{cm}^{2}$. Ensemble was bathed in ASW with $\left[\mathrm{Mg}^{2+}\right]=1 \mathrm{mM}$ during the experiment to excite some of the neurons. Cell $c$ was stimulated as indicated. $C$ : temporal firing patterns of the 3 cells in the ensemble that were active during the stimulus paradigm. Patterns were deduced from optical records in $B$. Initially, cell $a$ was tonically active and $b$ was quiescent. After the activation of $c$, the output of $a$ transiently stopped, whereas $b$ was transiently activated. $D$ : Summary of the signs of the functional neuronal connections in this circuit.

The classification was essentially unique when the $\mathrm{S} / \mathrm{N}$ ratio was large, $\mathrm{S} / \mathrm{N} \sim 10\left(\Delta A_{4}\right.$ in Fig. $\left.7 C\right)$. When the $\mathrm{S} / \mathrm{N}$ ratio was small, $\mathrm{S} / \mathrm{N} \leq 3$, the classification of individual events was often ambiguous $\left(\Delta A_{2}\right.$ in Fig. $\left.7 C\right)$. Nonetheless, the presence of ambiguous activity in the records from some regions was offset by the redundancy achieved by recording simultaneously from many regions. Spikes that occurred at essentially the same time $(\Delta t=1 \mathrm{~ms})$ in records from different regions were classified as originating from the same neuron. Their temporal and spatial distribution is indicated by the symbols in Fig. $7 C(\mathrm{O}, *, \triangle,+)$. The number of independent classifications was a measure of the number of active neurons (note that cell $a$ is not represented in the records in Fig. $7 C$ ). This procedure allowed us to determine the temporal firing patterns for the five cells in the ensemble (Fig. $7 E$ ), making exclusive use of the optical records. Similar, unique determinations of the spiking activity of simultaneously active neurons were made with other ensembles $(n=30)$.

DETERMINATION OF FUNCTIONAL CONNECTIONS. To illustrate the optical determination of functional connections, we focus on the results obtained with an ensemble that showed simple functional inhibitory and excitatory connections. The ensemble and the optical receptive fields subsumed by each of five consolidated (summed) photodetectors outputs are shown in Fig. $8 A$. The ensemble was superfused with low divalent ASW to induce tonic activation of as many neurons as possible. Cell $c$ was stimulated to fire transiently at a relatively high rate by the injection of depolarizing current-pulses.

An example of the optical changes recorded during the period of stimulation is shown in Fig. $8 B$. This record was used to construct the temporal firing patterns of individual neurons (Fig. $8 C$ ). Three cells in the ensemble were ob- served to spike within the time of the record. One cell, $a$, was tonically active. It stopped firing after $c$ was stimulated and then recovered to its initial, tonic firing rate (Fig. $8 C$ ). In contrast, $b$ was initially quiescent but was transiently activated subsequent to the stimulation of $c$ (Fig. $8 C$ ).

The data imply that cell $c$ makes an inhibitory functional connection with $a$ and a delayed, excitatory connection with $b$ (Fig. 8D). The inhibitory interaction from $c$ to $a$ was initiated immediately on the activation of $c$, whereas the delayed, excitatory interaction from $c$ to $b$ occurred after the stimulation of $c$.

It is unlikely that polysynaptic pathways had a role in determining the electrical activity of this neuronal ensemble. Over 100 neurons have been studied with conventional microelectrodes while being monitored simultaneously with potentiometric probes. A spike has never been recorded electrically that was not also detected optically, and thus we are confident of our ability to monitor optically all suprathreshold events. Furthermore, previous work (Parsons et al. 1989a) has demonstrated that the LUQ cells in vitro require high-frequency $(>1 \mathrm{~Hz})$ stimulation to elicit detectable synaptic transmission. Therefore only cell $c$, the cell into which current was injected, was a candidate for transmitter release in this ensemble (Fig. $8 \mathrm{C}$ ).

These results suggest that the same cell may express different functional connections with different follower cells in the same ensemble. Similar effects were seen with other ensembles $(n=6)$.

\section{Dynamic patterns of functional connectivity in neuronal ensembles}

The results described above establish methods for monitoring and interpreting the patterns of electrical activity generated by ensembles of neurons in vitro. We used these 

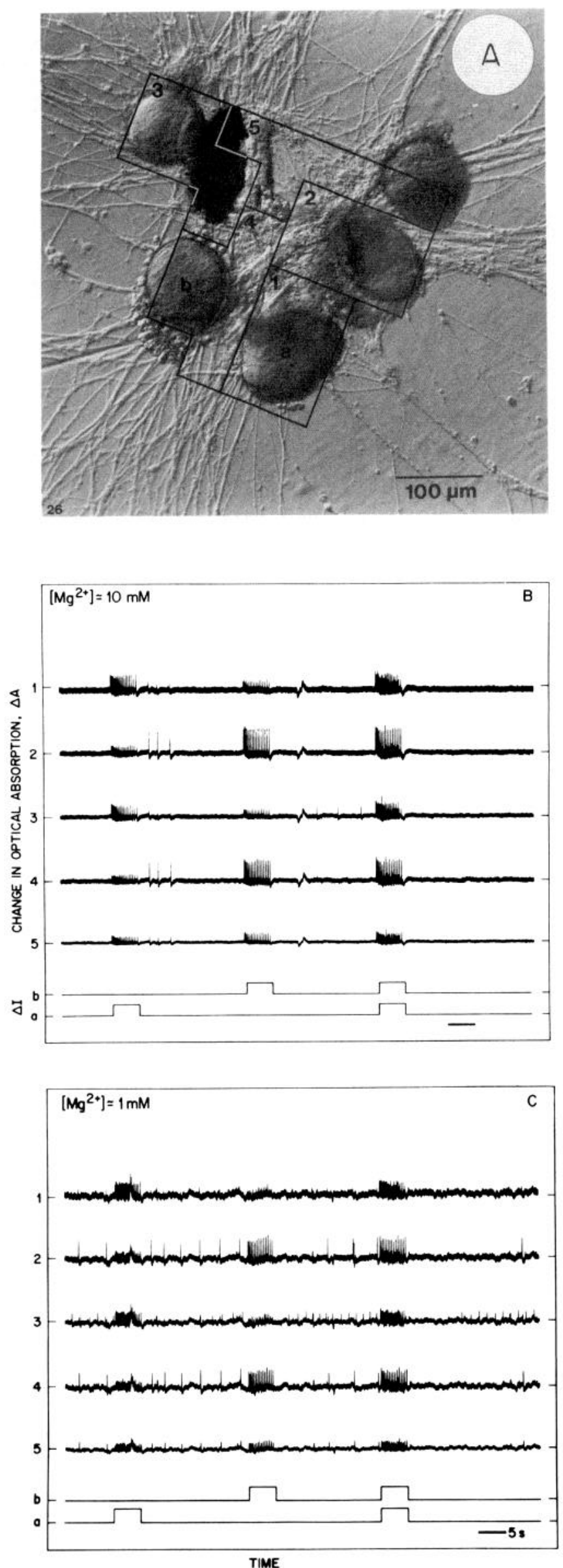

methods to analyze functional connectivity within neuronal ensembles under a variety of stimulus conditions. Because the probability of any two LUQ neurons forming a synaptic connection in vitro is considerably $<1$ (Parsons et al. 1989c) and the patterns of neuritic outgrowth are remarkably varied, each ensemble can thus be considered as a unique, anatomic circuit. Our analysis of one particularly interesting ensemble in which dynamic functional connectivity was observed is presented here.

PARADOXICAL PATTERNS OF FUNCTIONAL CONNECTIVITY. We describe the results obtained with an ensemble of five LUQ cells (Fig. 9A). Two of the neurons, designated $a$ and $b$, were stimulated either singly or jointly with intracellular injections of current. Examples of the optical records are shown in Fig. $9 B$. Although the $\left[\mathrm{Mg}^{2+}\right]$ in the ASW had been reduced to $\sim 10 \mathrm{mM}$, all of the cells were quiescent before stimulation (Fig. 9B). A delayed, excitatory response or no response at all was seen when cells $a$ and $b$ were stimulated.

The temporal firing patterns deduced from the optical records of Fig. $9 B$ are shown in Fig. 10, $A-C$. These indicate that three of the five neurons in the ensemble were active. The average activities obtained from repeated measurements under each experimental condition are displayed in the form of peristimulus time histograms (Fig. 10, D-F) (Glaser and Rushkin 1976). In each histogram, we averaged the number of spikes that occurred in consecutive 5-s intervals. This interval is the nominal time-scale of the underlying synaptic responses (Fig. 8) and preserved the essential features of the data.

A unique temporal firing pattern for each neuron was observed for every set of experimental conditions, i.e., stimulus paradigm (cf. Fig. 10, $A-C$ ). The features of the temporal firing patterns obtained in a given measurement compared favorably with those of the average response. This suggests that the essential features of the patterns were invariant when the stimulus paradigm was repeated and demonstrates the robust nature of the temporal firing patterns.

When the cells were quiescent, stimulating $a$ caused $b$ to fire transiently after a delay (Fig. $10, A$ and $D$ ). This is interpreted in terms of an excitatory functional connection from $a$ to $b$ (Fig. 10G). Stimulating $b$ caused $c$ to fire after a delay (Fig. 10, $B$ and $E$ ), implying that there is also an excitatory connection from $b$ to $c$ (Fig. 10H). Surprisingly, when $a$ and $b$ were stimulated together, there was no delayed output in either $b$ or $c$ (Fig. 10, $C$ and $F$ ). For this paradigm there were no functional connections between the neurons (Fig. 10I).

This analysis showed that dynamic functional connections can be observed between the cells of a neuronal ensemble in vitro. The temporal superimposition of two stimuli resulted in the paradoxical change in functional connec-

FIG. 9. A neuronal ensemble that exhibited dynamic functional connectivity. $A$ : photomicrograph of the ensemble of 5 LUQ cells. Outlined areas correspond to fields of 5 summed photodetector outputs. Intracellular electrodes were placed in cells $a$ and $b$ during the experiments. $B$ : optical records from the summed detector outputs for 3 stimulus paradigms: stimulation of $a$, stimulation of $b$, and concurrent stimulation of $a$ and $b$. Preparation was stained with the dye RH155 and illuminated at a wavelength of $700 \pm 5 \mathrm{~nm}$ and an intensity of $\sim 3 \mathrm{~mW} / \mathrm{cm}^{2}$. Ensemble was bathed in ASW with $\left[\mathrm{Mg}^{2+}\right]=10 \mathrm{mM}$ during this set of experiments. Note that none of the neurons were tonically active. 

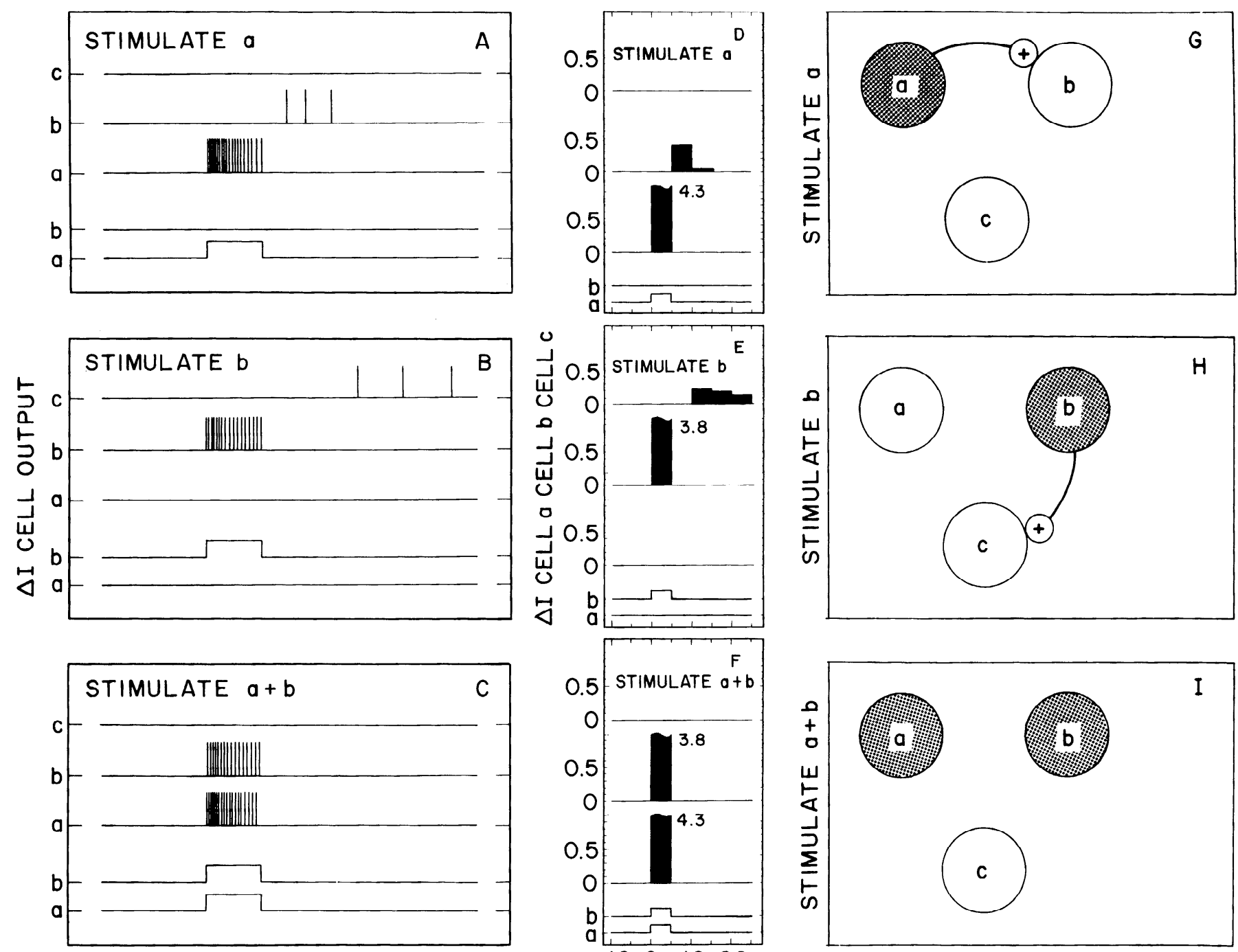

TIME
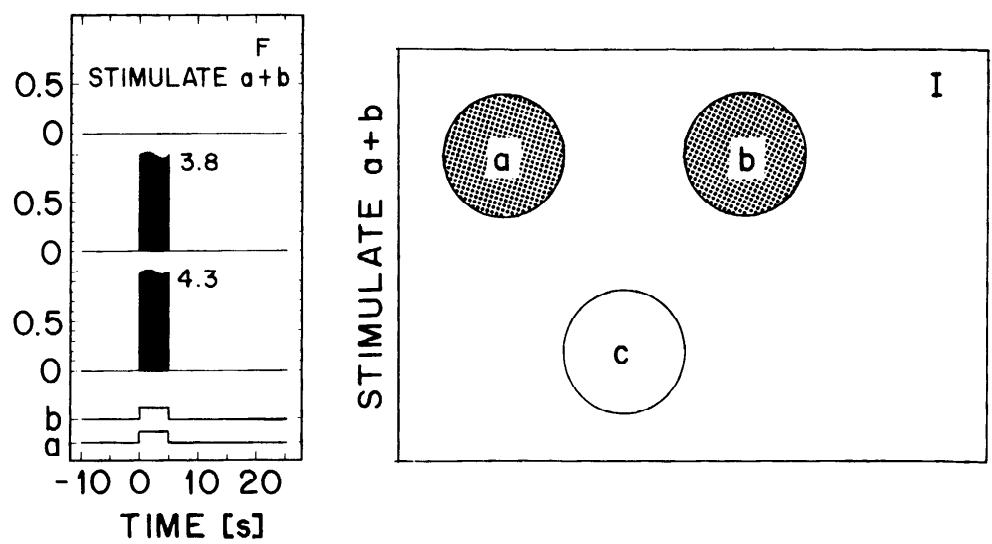

FIG. 10. Dynamic functional connectivity determined by different stimulation patterns. $A-C$ : temporal firing patterns derived from optical records in Fig. $9 B$. Each pattern correspond to a particular stimulus paradigm. $A$ : output after the stimulation of $a$ to fire action potentials when the ensemble was tonically quiescent. Stimulation resulted in the delayed activation of $b . B$ : output after the stimulation of $b$. A delayed excitatory response was observed in $c$. $C$ : output after coincident stimulation of $a$ and $b$. There is no delayed excitatory response in either $b$ or $c$. $D-F$ : peristimulus time histograms that show the average firing rate as a function of time for each of the stimulus paradigms. Seven independent measurements were made for each condition. Data were averaged in 5-s intervals. Note that the firing during the interval in which a cell was stimulated is indicated to the right of the (truncated) peak. $D$ : average output after the stimulation of $a$ when the ensemble was tonically quiescent. $E$ : output after stimulation of $b$. $F$ : output after coincident stimulation of $a$ and $b$. G-I: set of functional connections derived for each of the temporal firing patterns shown by histograms in $D-F$. Each schematic diagram shows the sign of the functional connection between 2 neurons.

tions between the neurons. The finding that the simultaneous presentation of two inputs that individually participate in excitatory functional connections produced no functional connections is intriguing. These results suggest that the concomitant activation of the two neurons negated the excitatory functional connections between them (i.e., cell $a$ to cell $b$ ), as well as onto another cell (i.e., cell $b$ to cell c).

UNMASKING OF INHIBITORY FUNCTIONAL CONNECTIONS. Manifestation of inhibitory functional connections depends on the presence of tonic activity in the postsynaptic cell (cf. Fig. 8). In an effort to identify any inhibitory functional connections within the ensemble, we reduced the bath concentration of $\left[\mathrm{Mg}^{2+}\right]$ to $\sim 1 \mathrm{mM}$ and repeated the stimulation paradigms. A fraction of the cells were tonically active in ASW with $\left[\mathrm{Mg}^{2+}\right] \sim 1 \mathrm{mM}$ (Fig. 9C). Under these conditions predominantly inhibitory effects are observed after stimulation of $a$ and $b$.

The temporal firing patterns deduced from the optical records of Fig. $9 C$ are shown in Fig. $11, A-C$. These indicate that two of the five neurons in the ensemble were activated tonically by the low divalent solution. A third neuron was induced to fire after intracellular current injection. These are the same three neurons that were active with $\left[\mathrm{Mg}^{2+}\right] \sim$ $10 \mathrm{mM}$ (cf. Fig. 10, $A-C$ ). The average activities obtained from repeated measurements under each experimental condition are displayed in the form of peristimulus time histograms (Fig. 11,D-F). A unique temporal firing pat- 

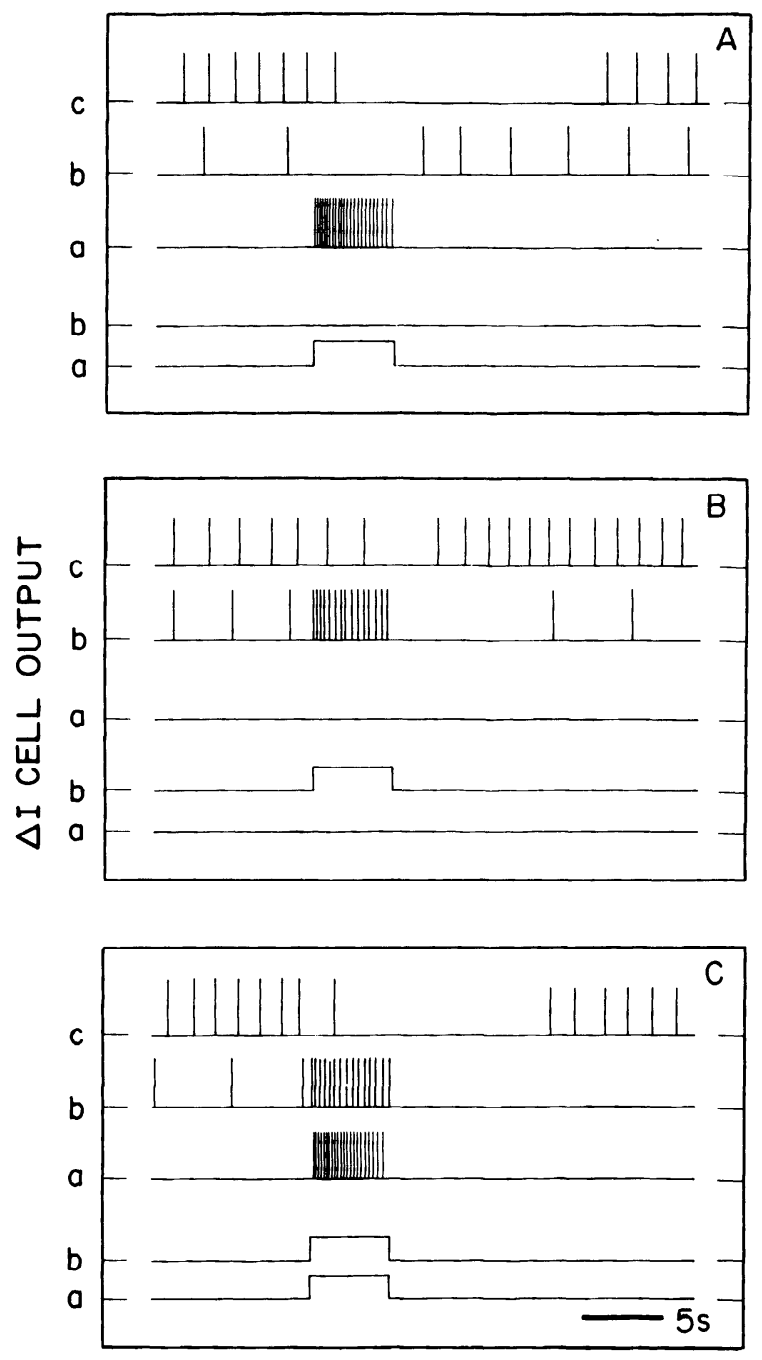

TIME
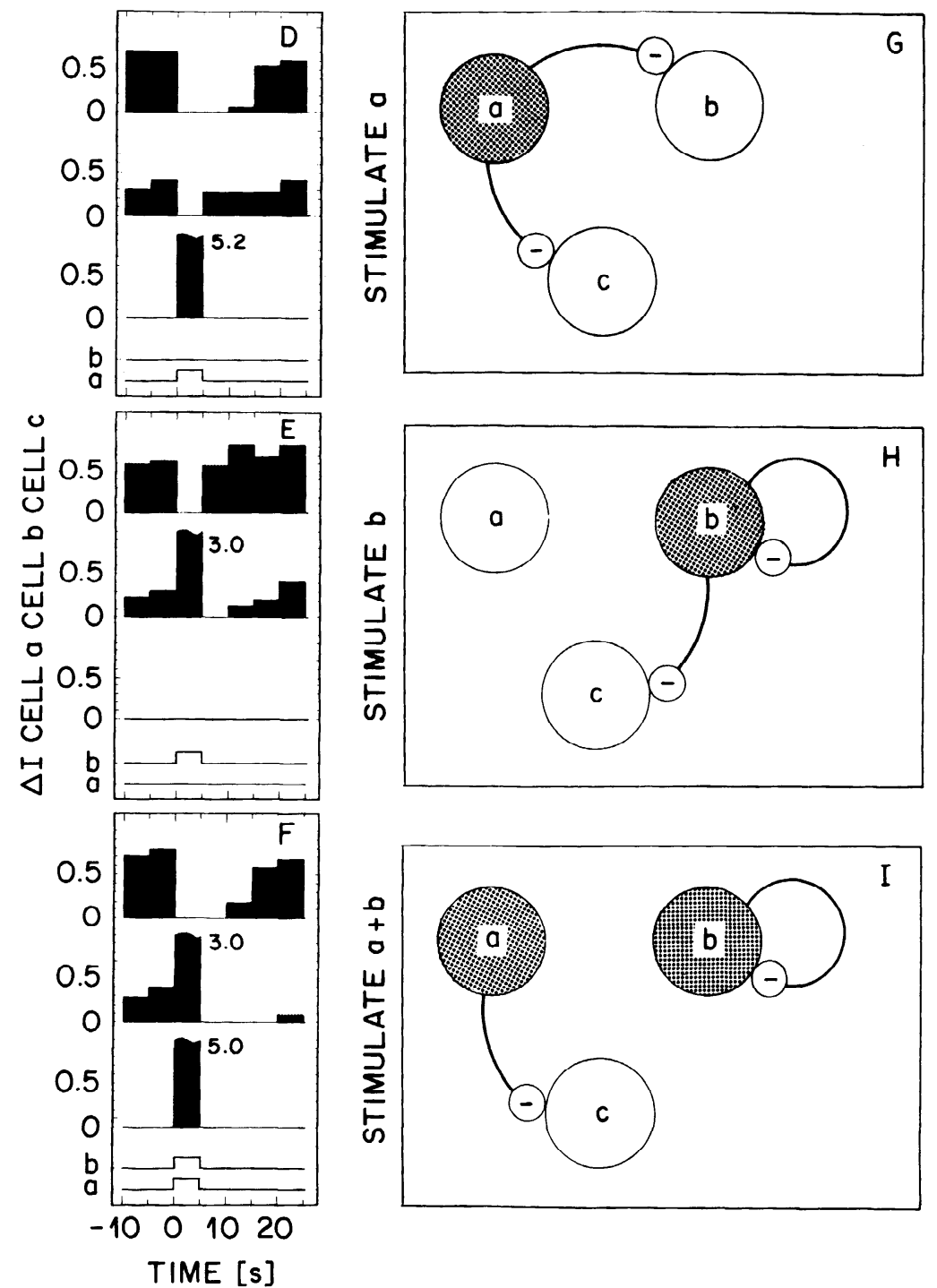

FIG. 11. Inhibitory functional connections revealed by tonic activity of a neuronal ensemble. $A-C$ : temporal firing patterns derived from optical records when the $\left[\mathrm{Mg}^{2+}\right]$ was lowered to activate the ensemble tonically. $A$ : output after stimulation of $a$ when cells $b$ and $c$ were tonically active. Stimulation of $a$ resulted in the transient cessation of activity in $b$ and $c$. B : output after stimulation of $b$. Stimulation resulted in the transient cessation of activity in $b$ and $c$. $C:$ output after coincident stimulation of $a$ and $b$. Transient cessation of activity was again observed in $b$ and $c$. $D-F$ : peristimulus time histograms that show the average firing rate as a function of time for each of the stimulus paradigms, as in Fig. 10. $D$ : output after stimulation of $a$ when $b$ and $c$ were tonically active. $E$ : output after stimulation of $b$. $F$ : output after coincident stimulation of $a$ and $b$. $G \sim I$ : set of functional connections when cells $b$ and $c$ were tonically active. Functional connections correspond to each of the temporal firing patterns shown by the histograms in $D-F$. Closed loops indicate autoinhibition. Note that, for the same stimulus paradigm, increasing the tonic level of activity reveals inhibitory interactions (compare Fig. 10, $G-I$, with Fig. 11, G-I.

tern for each neuron was observed for every set of experimental conditions, i.e., stimulus paradigm (cf. Fig. 11, $A-$ $C)$. These patterns of electrical activity demonstrated the same robust nature observed in the presence of higher $\left[\mathrm{Mg}^{2+}\right]$ (cf. Fig. 10, $A-F$ ).

Cells $b$ and $c$ were tonically active in ASW with $\left[\mathrm{Mg}^{2+}\right] \sim$ $1 \mathrm{mM}$. Stimulating a caused $b$ and $c$ transiently to stop firing (Fig. 11, $A$ and $D$ ). This was interpreted as the expression of inhibitory functional connections from $a$ to $b$ and to $c$ (Fig. $11 G$ ). Stimulating $b$ caused $c$ transiently to stop firing and $b$ to stop firing briefly after cessation of the stimulus (Fig. 11, $B$ and $E$ ). This is interpreted as the expression of an inhibitory functional connection from $b$ to $c$ and an autoinhibitory functional connection onto $b$ (Fig. $11 H$ ). The transient cessation of activity observed in $c$ when $a$ and $b$ were stimulated together (Fig. 11, $C$ and $F$ ) could not be interpreted in terms of a single set of functional connections; the simplest possibility is shown in Fig. $11 I$.

BASIS FOR DYNAMIC FUNCTIONAL CONNECTIVITY. The different sets of coexisting functional connections in the ensemble of LUQ cells illustrated here (Figs. 10, $G-I$, and 11, G-I) can be understood in terms of the cellular and synaptic properties of the LUQ neurons. The delayed excitatory responses observed in $b$ after stimulation of $a$, or in $c$ after stimulation of $b$ (Fig. 10, $D$ and $E$, respectively), are consistent with the delayed excitation produced by a dual-action synapse (Fig. 3B). Note that when $b$ was excited by $a$ (Fig. $10 D$ ), the firing rate in $b$ was too low, $\sim 0.5$ spikes/s, to excite $c$ in turn. 


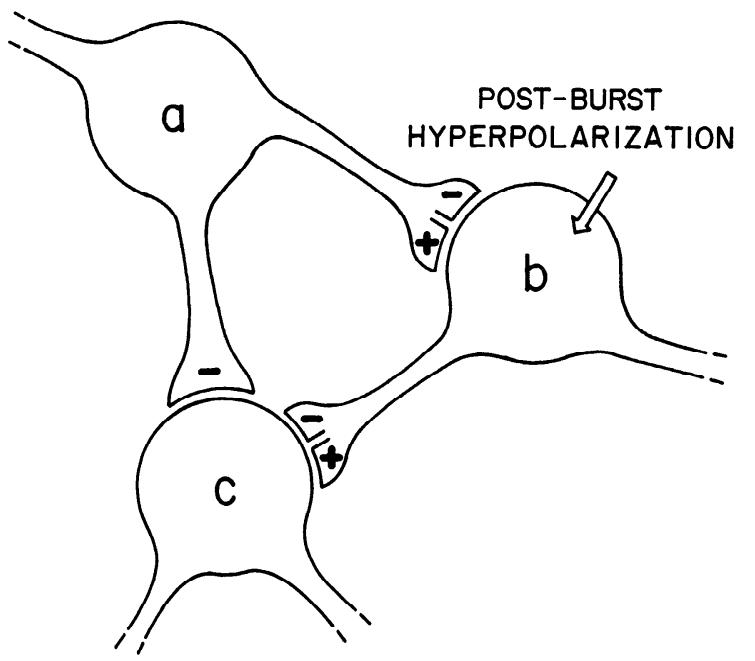

FIG. 12. Schematic of the underlying synaptic connections deduced from the different patterns of functional connectivity shown in Figs. 10 and 11 . Boutons marked \pm are dual-action synapses, with inhibition followed by delayed excitation. All of these neurons exhibited the cellular property of postburst hyperpolarization. This was the substrate for autoinhibitory functional connections (Fig. 11, $H$ and $I$ ).

Two time-scales were present for the decay of the inhibitory responses observed in $b$ and $c$. The long-lasting inhibition of $c$ after the stimulation of $a$ (Fig. 11D) suggests that the underlying connection from $a$ to $c$ was a solely inhibitory synapse (Fig. 3A). In contrast, the inhibition of $b$ caused by the stimulation of $a($ Fig. $11 D$ ) decayed relatively rapidly (Fig. $11 D$ ). This suggests that the underlying connection from $a$ to $b$ was a dual-action synapse; the delayed excitation shortens the time scale of the inhibitory response (Fig. 3B). Similarly, the inhibition of $c$ caused by stimulation of $b$ (Fig. $11 E$ ) decayed relatively rapidly (Fig. $11 E$ ), suggesting that the underlying connection from $b$ to $c$ was also a dual-action synapse.

An autoinhibitory response was observed for $b$ (Fig. 11E) when the cell was otherwise tonically active $\left(\left[\mathrm{Mg}^{2+}\right] \sim 1\right.$ $\mathrm{mM})$. This response is consistent with the cellular property of post-burst hyperpolarization observed in LUQ neurons (Fig. $2 D$ ). Post-burst hyperpolarization provides a relatively long-lived inhibition in $b$ compared with the response that is mediated by the synapse from $a$ to $b$ (cf. Fig. $11, D$ and $E$ ). Thus the decay of the inhibitory response in $b$ appears to be governed by the decay of the postburst hyperpolarization, as opposed to synaptic inhibition from $a$, when $a$ and $b$ were stimulated simultaneously (Fig. $11 F$ ).

The underlying cellular properties and synaptic connections that account for all the different sets of functional connections we inferred are summarized in Fig. 12. This summary suggests why there were no functional connections between neurons $a$ and $b$ when they were stimulated simultaneously (Fig. 10, $C$ and $F$ ). The delayed excitatory response in $b$ was canceled by the postinhibitory hyperpolarization in $b$, and the delayed excitatory response in $c$ was canceled by the purely inhibitory input from $a$. These inhibitory effects were observed directly when the neurons were tonically active (Fig. 11, $D$ and $E$ ).

\section{DISCUSSION}

The present study has demonstrated that potentiometric probes, in conjunction with multiple-site optical recording techniques, can be used for the long-term recording of electrical activity from many neurons in vitro. Identified invertebrate neurons were used to construct ensembles of four to six cells in culture (Fig. 5). Optical measurements, made at suitably low levels of illumination, allowed us to monitor the extrinsic optical signals for up to $3 \mathrm{~h}$. The signal-tonoise ratio was adequate for the detection of single spikes (Figs. 8 and 9). Further, the spike trains of individual neurons could be reconstructed from the optical signals obtained from neuronal ensembles in which the neurite outgrowth was exuberant and in which all of the neurons were active simultaneously (Fig. 7). This information was used to infer the functional connections between the neurons within the ensemble (Fig. 8). Apparently paradoxical interactions between neurons within ensembles of four to six LUQ cells were observed when different stimulus paradigms were used at the same tonic level of activity (cf. Fig. $10, D, E, G$, and $H$ with $F$ and $I$ ). Different firing patterns and functional connections were also observed for the same input stimulus when we modulated the tonic activity of the neurons (cf. Figs. 10, D-I, with $11, D-I$ ). The results demonstrate that the same anatomic circuit in vitro can exhibit a dynamic repertoire of functional connectivity (cf. Figs. $10, G-I$, and $11, G-I)$. Observations of the underlying cellular and synaptic properties of LUQ cells in vitro (Figs. 2 and 3) allowed us to explain the generation of multiple patterns of electrical activity and functional connectivity as the result of their interplay (Fig. 12).

\section{Multiple-site optical recording in vitro}

A number of previous studies have addressed the issue of recording the activity of neurons in culture. Parsons et al. (1989a) used optical methods to observe the activity of pairs of LUQ neurons that interacted via inhibitory connections. Relatively high intensities of illumination, $\sim 2 \mathrm{~W} / \mathrm{cm}^{2}$, were used in those experiments so that details of the action potentials could be resolved. This limited the recording time to $\leq 30 \mathrm{~s}$ and necessitated the removal of oxygen from the medium to avoid photodynamic damage. Other optical studies of neurons in vitro considered only single cells (Grinvald et al. 1981b, 1982, 1983; Ross et al. 1987; Ross and Reichardt 1979).

\section{Long-term optical recording}

In the present study, we have assessed the relation between the long-term viability of the preparation during optical measurements and the signal-to-noise ratio of the optical changes accompanying a spike (Fig. 2). This allowed us to optimize $\mathbf{I}_{0}$ so that the spiking activity from ensembles of neurons could be recorded continuously for periods up to 3 h. The firing characteristics of the neurons and the spatial distribution of activity over the arborization of the neurons remained constant over this period. Our recording time was $10^{3}$ to $10^{5}$ times longer than that achieved in previous studies (Grinvald et al. 1981b-1983; Parsons et al. 1989a). The consolidated detectors could be positioned selectively over an arbitrary arrangement of cells.

The resolution of several unexplored technical issues may further improve the utility of potentiometric probes and multiple-site optical recording techniques. In particular, the signal-to-noise ratio in optical experiments is often 
limited by technical noise (Fig. $4 B$ ). This situation might be ameliorated by the use of rapid, alternating measurements at two different wavelengths (e.g., $\lambda=660$ and $700 \mathrm{~nm}$; Fig. $4 A$ ) together with phase-sensitive detection techniques (Cardona 1969). Finally, higher resolution (more pixels) diode arrays should permit more nearly optimal spatial binning (consolidation) of the detectors.

\section{Analysis of optical data}

We were able to reconstruct the spike trains of individual neurons from the optical records by the use of relatively simple procedures. Our analysis made use of the differences in the amplitude of spikes observed from each of the summed detector outputs and the distribution of coincident spikes recorded from different spatial fields (Figs. 6 and 7). It allowed us to deduce, by hand, the spike trains for individual neurons within tangled ensembles of simultaneously active cells (Fig. 7). Essentially identical procedures have allowed others to detect the individual activity of several hundred Aplysia neuron somata in situ in the abdominal ganglion (Nakashima et al. 1989; Zecevic et al. 1989). With larger or more complex culture systems, it may be advantageous to use algorithms that have been devised to compute spike trains from extracellular cortical records (Abeles and Goldstein 1977; Salganicoff et al. 1988; Schmidt 1984). Note that none of the methods used to reconstruct spike trains can determine whether a signal originates from a single cell or from two cells that are coupled through strong electrotonic connections or shared inputs.

\section{Neuronal properties of LUQ cells in vitro}

We examined the cellular properties of individual LUQ neurons in vitro and the properties of synapses between cocultured LUQ neurons. Some of these properties were different from those reported for LUQ neurons in vivo (Frazier et al. 1967). However, all of the properties that we observed with cultured LUQ cells have been observed for Aplysia neurons other than LUQ cells in vivo.

The LUQ cells could be stimulated to fire tonically in vitro either by the injection of intracellular current or by lowering $\left[\mathrm{Mg}^{2+}\right]$ in the external medium (Fig. 2, $A$ and $B$ ). Rhythmic bursting characteristic of LUQ cells in vivo (Kramer and Zucker 1985; Scholtz et al. 1988) was not observed in any of the LUQ cells used in these experiments. [However, under slightly different conditions, burst behavior typical of LUQs in situ was seen (Obaid et al. 1989).] The tonic, nonbursting output observed most often in vitro may result from some of the procedures used to isolate the neurons and maintain them in culture. However, we used the same procedures to culture neuron R15 and observed that it did produce rhythmic firing patterns in vitro identical to those in vivo (Fig. $2 C$ ).

Cultured LUQ neurons were capable of firing at a constant low rate for periods of $\geq 20 \mathrm{~min}$. However, tonically active neurons hyperpolarized after the termination of a current-pulse that induced a period of rapid spiking. The postburst hyperpolarization lasted for $20-40 \mathrm{~s}$, after which the cells resumed firing at their original rate (Fig. $2 D$ ). Cessation of activity did not occur when $500 \mu \mathrm{M} \mathrm{Cd}^{2+}$, a known blocker of $\mathrm{Ca}^{2+}$ currents, was added to the external medium. These results can be explained by the presence of a Ca ${ }^{2+}$-activated K+ $\mathrm{K}^{+}$-current (e.g., Meech 1979; Meech and Strumwasser 1970).

Co-cultured LUQ neurons formed synaptic connections in vitro that are not observed in vivo. In this sense, they are novel. The most prevalent synapse had a solely inhibitory response that decayed with biphasic kinetics and that could be nulled, but not reversed, by hyperpolarizing the postsynaptic neuron (Fig. 3A). This was consistent with the action of these neurotransmitters on LUQ cells in vivo (Brezina 1987). Inhibitory connections that behaved similarly to those observed here have been characterized for other neurons from the abdominal ganglion in vivo (Kehoe 1972b). Novel inhibitory connections have also been observed between other co-cultured Aplysia neurons (Bodmer et al. 1984; Kleinfeld et al. 1990c; Parsons et al. 1989c; Schacher 1988; Schacher et al. 1985).

A fraction of the co-cultured LUQ neurons formed a novel dual-action synapse, with inhibition followed by a delayed excitation (Fig. $3 B$ ). The inhibitory part of the response behaved similarly to the solely inhibitory connection (cf. Fig. 3, $A$ and $B$ ). The excitatory response was present if the inhibition was nulled by hyperpolarizing the postsynaptic cell (Fig. 3B). This and other evidence suggests that the excitation is a synaptic effect and does not result from a cellular property such as postinhibitory rebound. The dual-action response observed here resembles the response recorded in vivo from medial cells in the left pleural ganglion of Aplysia (Kehoe 1985). Synapses with multiplc action on the same postsynaptic cell have also been observed in a large variety of other nervous systems, both in vertebrates (Dodd and Horn 1983; Hartzell et al. 1977; Kuffler 1980; Tosaka et al. 1968) and in invertebrates (Ascher 1972; Gardner 1977; Gardner and Kandel 1977; Gerschenfeld and Paupardin-Tritsch 1974; Getting 1981, 1983; Wachtel and Kandel 1971).

\section{Functional connectivity}

We used the multiple-site optical recording methods to measure the spiking output of the neurons in the ensemble. These methods, in combination with intracellular stimulation of some of the neurons, allowed us to extract the temporal firing patterns of the individual neurons in ensembles under a variety of experimental conditions (Figs. 8, 10, and 11). The ability to determine simultaneously the output from all of the neurons allowed us to analyze the properties of very many ensembles, a task that would have been prohibitive if we had used microelectrodes. This was crucial for the present study, as only a fraction of the LUQ neurons developed interesting synaptic interactions.

A particularly interesting aspect of our results was that the firing pattern observed when two cells were stimulated together could not be predicted from the patterns observed when the cells were stimulated individually. Excitatory functional connections were inferred, using ASW with a high concentration of $\mathrm{Mg}^{2+}$, when each cell was stimulated separately (Fig. 10, $A$ and $B$ ). In contrast, no functional connections were present when the cells were stimulated jointly (Fig. $10 \mathrm{C}$ ). The apparent lack of connectivity arose from canceling the excitatory inputs either by a second inhibitory input (cell $c$, Fig. 12) or by activation of the cellular property of postburst hyperpolarization (cell $b$, Fig. 12). 
These inhibitory interactions within the ensemble were only revealed after the tonic activity of the neurons had been increased (Fig. 11). Our results emphasize a serious limitation inherent in the use of functional connectivity as an approach to understanding neuronal circuitry, viz., the difficulty in recognizing inhibitory interactions (for further discussion see Aertsen et al. 1989).

In summary, the optical methods described here allow one to attain long recording times, reconstruct the temporal firing patterns of individual cells, and determine the functional connectivity of a neuronal ensemble constructed from at least six identified cells. These methods, in combination with conventional characterization of cellular and synaptic responses, can be used to begin to understand the collective behavior of defined neuronal ensembles or networks. To that end, we have illustrated how the interplay among the cellular and synaptic properties of neurons can generate dynamic patterns of functional connectivity within a single neuronal ensemble in vitro.

We thank T. W. Abrams, L. B. Cohen, K. Delany, A. Gelperin, G. L. Gerstein, A. Kay, R. A. Stepnoski, and R. E. Slusher for useful discussions; B. Friedman for critical comments on an earlier version of the manuscript; and T. R. Capo and the Howard Hughes Medical Foundation for generously supplying us with Aplysia.

This work was supported by AT\&T Bell Laboratories and a National Institutes of Health Grant NS-16824 to B. M. Salzberg and A. L. Obaid. T. D. Parsons was supported by the Veterinary Medical Scientist Training Program and NIH Training Grant HL-07499.

Present address of T. D. Parsons: Dept. of Anatomy and Cell Biology, Emory University School of Medicine, Atlanta, GA 30322.

Address for reprint requests: B. M. Salzberg, Dept. of Physiology, B-400 Richards Building, University of Pennsylvania School of Medicine, Philadelphia, PA 19104-6085.

Received 19 October 1990; accepted in final form 27 February 1991.

NOTE ADDED IN PROOF

Recent studies by Chien and Pine ( $J$. Neurosci. Methods In Press 1991; Biophys. J. In press 1991) address the possibility of assaying circuit behavior in small co-cultures of mammalian neurons using multiple-site optical recording in conjunction with potentiometric dyes.

\section{REFERENCES}

ABELES, M. AND GoldSTEIN, M. Multispike train analysis. IEEE Proc. 65: 762-773, 1977.

ADAMS, W. B. AND BENSON, J. A. The generation and modulation of endogenous rhythmicity in the Aplysia bursting pacemaker neurone R15. Prog. Biophys. Mol. Biol. 46: 1-49, 1985.

Aertsen, A. M. H. J., Gerstein, G. L., Habib, M. K., Palm, G., Gochin, P., AND KRUGER, J. Dynamics of neuronal firing correlation: modulation of "effective connectivity". J. Neurophysiol. 61: 900-917, 1989.

ASCHER, P. Inhibitory and excitatory effects of dopamine on Aplysia neurones. J. Physiol. Lond. 225: 173-209, 1972.

BENNETT, M. V. L. Electrical transmission: a functional analysis and comparison to chemical transmission. In: Handbook of Physiology. The Nervous System. Cellular Biology of Neurons Bethesda, MD: Am. Physiol. Soc., 1977, sect. 1, vol. I, p. 357-416.

BLASDEL, G. G. Topography of visual function as shown with voltage-sensitive dyes. In: Sensory Processing in the Mammalian Brain: Neural Substrates and Experimental Strategies, edited by J. S. Lund. New York: Oxford Univ. Press, 1989, p. 242-268.

BoDMER, R., DAGAN, D., AND LeVITAN, I. B. Chemical and electrotonic connections between Aplysia neurons in primary culture. J. Neurosci. 4: 228-233, 1984.

BREZINA, V. Acetylcholine and FMRFamide acting through different receptors, both activate "S"-like $\mathrm{K}$ current and supress Ca current in Aplysia neurons. Soc. Neurosci. Abstr. 13: 704, 1987.

BURKe, R. E. AND RUDOMIN, P. Spinal neurons and synapses. In: Handbook of Physiology. The Nervous System. Cellular Biology of Neurons.
Bethesda, MD: Am. Physiol. Soc., 1977, scct. 1, vol. I, part 2, p. $877-$ 944.

Camardo, J., Proshansky, E., AND Schacher, S. Identified Aplysia neurons form specific chemical synapses in culture. J. Neurosci. 3: 2614$2620,1983$.

CARDONA, M. Modulation spectroscopy. In: Solid State Physics: Advances in Research and Applications (Suppl. 11), edited by F. Seitz, D. Turnbull, and H. Ehrenreich. New York: Academic Press, 1969.

COHEN, L. B. AND LESHER, S. Optical monitoring of membrane potential: methods of multisite optical measurement. In: Optical Methods in Cell Physiology, edited by P. DeWeer and B. M. Salzberg. New York: Wiley, 1986, p. 71-99.

Cohen, L. B. AND SalzberG, B. M. Optical measurements of membrane potential. Rev. Physiol. Biochem. Pharmacol. 83: 35-88, 1978.

DAGAN, D. AND LEVITAN, I. B. Isolated identified Aplysia neurons in cell culture. J. Neurosci. 1: 736-740, 1981.

DELCOMYN, F. Neural basis of rhythmic behavior in animals. Science Wash. DC 210: 2727-2731, 1980.

DODD, J. AND HORN, J. P. Muscarinic inhibition of sympathetic C neurones in the bullfrog. J. Physiol. Lond. 334: 271-291, 1983.

FRANKENHAEUSER, B. AND HoDGKIN, A. L. The action of calcium on the electrical properties of squid axons. J. Physiol. Lond. 137: 218-244, 1957.

Frazier, W. T., Kandel, E. R., KupfermanN, I., WAZIRI, R., AND CoGGESHALL, R. E. Morphological and functional properties of identified neurons in the abdominal ganglion of Aplysia californica. J. Neurophysiol. 30: 1288-1351, 1967.

GARDNER, D. Interconnections of identified multiaction interneurons in buccal ganglia of Aplysia. J. Neurophysiol. 40: 349-361, 1977.

GARDNER, D. AND KANDEL, E. R. Physiological and kinetic properties of cholinergic receptors activated by multiaction interneurons in the buccal ganglia of Aplysia. J. Neurophysiol. 40: 333-348, 1977.

GeRSCHENFELD, H. M. AND PAUPARDIN-TRITSCH, D. Ionic mechanism and receptor properties underlying the responses of molluscan neurones to 5-hydroxytryptamine. J. Physiol. Lond. 243: 427-456, 1974.

GETTING, P. A. Mechanisms of pattern generation underlying swimming in Tritonia. I. Neuronal network formed by monosynaptic connections. J. Neurophysiol. 46: 151-164, 1981.

GETTING, P. A. Mechanisms of pattern generation underlying swimming in Tritonia. III. Intrinsic and synaptic mechanisms for delayed excitation. J. Neurophysiol. 49: 1036-1050, 1983.

GETTING, P. A. Emerging principles governing the operation of neuronal networks. Annu. Rev. Neurosci. 12: 185-204, 1989a.

GetTing, P. A. Reconstruction of small neural networks. In: Methods in Neuronal Modeling: From Synapses to Networks. cdited by C. Koch and I. Segev. Cambridge, MA: MIT Press, 1989b, p. 171-194.

GlaSER, E. M. AND RuShKIN, D. S. Principles of Neurobiological Signal Analysis. New York: Academic, 1976.

Grinvald, A., Cohen, L. B., Lesher, S., ANd Boyle, M. B. Simultaneous optical monitoring of activity of many neurons in invertebrate ganglia using a 124-element photodiode array. J. Neurophysiol. 45: 829840,1981 a.

Grinvald, A., Fine, A., FARber, I. C., AND Hildesheim, R. Fluorescence monitoring of electrical responses from small neurons and their processes. Biophys. J. 42: 195-198, 1983.

Grinvald, A., Frostig, R. D., Lieke, E., AND Hildesheim, R. Optical imaging of neuronal activity. Physiol. Rev. 68: 1285-1366, 1988.

Grinvald, A., Hildesheim, R., FARBER, I. C., AND ANGlister, L. Improved fluorescence probes for the measurement of rapid changes in membrane potential. Biophys. J. 39: 301-308, 1982.

Grinvald, A., Hildesheim, R., Gupta, R., AND Cohen, L. B. Better fluorescent probes for optical measurement of membrane potential. Biol. Bull. Mar. Biol. Lab. 159: 484, 1980.

GRINVALD, A., Ross, W. N., AND FARBER, I. C. Simultaneous optical measurements of electrical activity from multiple sites on the processes of cultured neurons. Proc. Natl. Acad. Sci. USA 78: 3245-3249, $1981 \mathrm{~b}$.

HABERLY, L. B. Neural circuitry in olfactory cortex: Anatomy and functional implications. Chem. Senses. 10: 219-238, 1985.

Hartzell, H. C., Kuffler, S. W., Stickgold, R., and Yoshikami, D. Synaptic excitation and inhibition resulting from direct action of acetylcholine on two types of chemoreccptors on individual amphibian parasympathetic neurones. J. Physiol. Lond. 271: 817-846, 1977.

HubEL, D. H. AND WIESEL, T. N. Functional architecture of macaque monkey visual cortex. Proc. R. Soc. Lond. B Biol. Sci. 198: 1-59, 1977.

KEHOE, J. Ionic mechanisms of a two-component cholinergic inhibition in Aplysia neurones. J. Physiol. Lond. 255: 85-114, 1972a. 
KeHOE, J. Three acetylcholine receptors in Aplysia neurones. J. Physiol. Lond. 255: 115-146, 1972b.

KEHOE, J. Synaptic block of a transmitter-induced potassium conductance in Aplysia neurones. J. Physiol. Lond. 369: 399-437, 1985.

KINGSTON, R. H. Detection of Optical and Infrared Radiation. New York: Springer-Verlag, 1978.

KLEINFELD, D., CHIEL, H. J., AND SOMPOLINSKY, H. Small nervous systems and neural network models. In: Nonlinear Dynamics and Neuronal Networks. edited by H. G. Schuster and W. Singer. Weinheim, FRG: VCH. In Press.

Kleinfeld, D., KAhler, K. R., AND Hockberger, P. E. Controlled outgrowth of dissociated neurons on patterned substrates. J. Neurosci. 8: 4098-4120, 1988.

Kleinfeld, D., Parsons, T. D., Raccuia-Behling, F., Obaid, A. L., AND SALZBERG, B. M. Synaptic interactions in assemblies of cultured Aplysia neurons. I. Analysis of optically recorded electrical activity. Soc. Neurosci. Abstr. 15: 1140, 1989.

Kleinfeld, D., Parsons, T. D., Raccuia-Behling, F., Salzberg, B. M., AND OBAID, A. L. Foreign connections are formed in vitro among Aplysia neuron L 10 and its in vitro followers and non-followers. J. Exp. Biol. 154, 237-255, 1990c.

Kleinfeld, D., Raccuia-Behling, F., and Chiel, H. J. Circuits constructed from identified Aplysia neurons exhibit multiple patterns of persistent activity. Biophys. J. 57: 697-715, 1990b.

KoCH, C. AND SEGEV, I. (Editors). Methods in Neuronal Modeling: From Synapses to Networks. Cambridge, MA: MIT Press, 1989.

KOESTER, J. AND AlEvizos, A. Innervation of the kidney of Aplysia by L10, the LUQ cells, and an identified peripheral motoneuron. J. Neurosci. 9, 4078-4088, 1989.

Kramer, R. H., Levitan, E. S., Carrow, G. M., and Levitan, I. B. Modulation of a subthreshold calcium current by the neuropeptide FMRFamide in Aplysia neuron R15. J. Neurophysiol. 60: 1728-1738, 1988.

KRAMER, R. H. AND ZUCKER, R. S. Calcium-induced inactivation of calcium current causes the interburst hyperpolarization of Aplysia bursting pacemaker neurons. J. Physiol. Lond. 362: 131-160, 1985.

KRISTAN JR., W. B. Generation of rhythmic motor patterns. In: Information Processing in the Nervous System, edited by H. M. Pinsker and W. D. Willis, Jr. New York: Wiley, 1980, p. 241-261.

KUFFLER, S. W. Slow synaptic responses in autonomic ganglia and the pursuit of a peptidergic transmitter. J. Exp. Biol. 89: 257-286, 1980.

LONDON, J. A., ZECEvic, D., AND CoHEN, L. B. Simultaneous optical recording of activity from many neurons during feeding in Navanax. $J$. Neurosci. 7: 649-661, 1987.

Lund, J. S. (Editor). Sensory Processing in the Mammalian Brain: Neural Substrates and Experimental Strategies. New York: Oxford Univ. Press, 1989.

MEECH, R. W. Membrane potential oscillations in molluscan "burster" neurones. J. Exp. Biol. 81: 93-112, 1979.

MEECH, R. W. AND STRUMWASSER, F. Intracellular calcium injection activates potassium current in Aplysia nerve cells (Abstract). Federation Proc. 29: 834, 1970.

Motchenbacher, C. A. AND Fitchen, F. C. Low Noise Electronic Design. New York: Wiley, 1973.

NaKashima, M., Yamada, S., Shino, S., AND MaEda, M. A 448-channel optical monitoring of neural signals from Aplysia ganglion. Soc. Neurosci. Abstr. 15: 1046, 1989.

Obaid, A. L., Kleinfeld, D., Parsons, T. D., Raccuia, G. F., AND SALZBERG, B. M. R15 and other rhythmically active Aplysia neurons exhibit endogenous bursting in culture: possible role as actuators of in vitro neuronal ensembles (Abstract). Biophys. J. 55: 175a, 1989.

Parsons, T. D., Kleinfeld, D., Raccuia-Behling, F., AND SAlzberG, B. M. Optical recording of the electrical activity of synaptically interacting Aplysia neurons in culture using potentiometric probes. Biophys. $J$. 56: 213-221, 1989a.

Parsons, T. D., Obaid, A. L., Kleinfeld, D., and Salzberg, B. M. Continuous long-term optical recording from identified Aplysia neurons in culture (Abstract). Biophys. J. 55: 174a, 1989b.

Parsons, T. D., Raccuia-Behling, F., Salzberg, B. M., and KleinFELD, D. Novel synaptic connections are formed among identified Aplysia neurons in culture (Abstract). Biophys. J. 55: 175a, 1989c.

Parsons, T. D., SalzberG, B. M., Obaid, A. L., Raccuia-Behling, F., AND KLEINFELD, D. Synaptic interactions in assemblies of cultured Aplysia neurons. II. Dynamic patterns of effective connectivity. Soc. Neurosci. Abstr. 15: 1140, 1989d.

Ross, W. N., ARECHIGA, H., AND Nicholls, J. G. Optical recording of calcium and voltage transients following impulses in cell bodies and processes of identified leech neurons in culture. J. Neurosci. 7: 38773887, 1987.

Ross, W. N. AND REICHARDT, L. B. Species-specific effects on the optical signals of voltage-sensitive dyes. J. Membr. Biol. 48: 343-356, 1979.

Salganicoff, M., Sarna, M., Sax, L., and Gerstein, G. L. Unsupervised waveform classification for multi-neuron recordings: a real-time, software-based system: I. algorithms and implementation. J. Neurosci. Methods 25: 181-187, 1988.

SALZBERG, B. M. Optical recording of voltage changes in nerve terminals and in fine neuronal processes. Annu. Rev. Physiol. 51: 507-526, 1989.

SAlzBERG, B. M., DAVILA, H. V., AND COHEN, L. B. Optical recording of impulses in individual neurons of an invertebrate central nervous system. Nature Lond. 246: 508-509, 1973.

Salzberg, B. M., Grinvald, A., Cohen, L. B., Davila, H. V., AND Ross, W. N. Optical recording of neuronal activity in an invertebrate central nervous system: simultaneous monitoring of several neurons. $J$. Neurophysiol. 40: 1281-1291, 1977.

SalzberG, B. M., Obaid, A. L., Senseman, D. M., And Gainer, H. Optical recording of action potentials from vertebrate nerve terminals using potentiometric probes provides evidence for sodium and calcium components. Nature Lond. 306: 36-40, 1983.

SATTERLIE, R. S. Reciprocal inhibition and postinhibitory rebound produce reverberation in a locomotor pattern generator. Science Wash. DC 229: 402-404, 1985.

SCHACHER, S. Identified Aplysia neurons maintained in dissociated cell culture: regeneration, synapse formation and synaptic plasticity. In: Cell Culture Approaches to Invertebrate Neuroscience, edited by D. J. Beadle, G. Lees, and S. B. Kater. New York: Academic, 1988, p. 53-84.

SCHACHER, S. AND PROSHANSKY, E. Neurite regeneration by Aplysia neurons in dissociated cell culture: modulation by Aplysia hemolymph and the presence of the initial axonal segment. J. Neurosci. 3: 2403-2413, 1983.

SChaCher, S., Rayport, S. G., AND Ambron, R. T. Giant Aplysia neuron R2 reliably forms strong chemical connections in vitro. J. Neurosci. 5: 2851-2856, 1985.

SCHMIDT, E. Computer separation of multi-unit neuroclectric data. $J$. Neurosci. Methods 12: 95-111, 1984.

SChOlZ, K. P., Cleary, L. J., AND BYRne, J. H. Inositol 1,4,5 trisphosphate alters bursting pacemaker activity in Aplysia neurons: voltage clamp analysis of effects on $\mathrm{Ca}^{2+}$ channels. J. Neurophysiol. 60: 86-104, 1988.

SELVERSTON, A. I. Are central pattern generators understandable? Brain Behav. Sci. 3: 535-571, 1980.

SELVERSTON, A. I. (Editor). Model Neural Networks and Behavior. New York: Plenum, 1985.

Spira, M., Segev, I., Werman, R., And Yarom, Y. Modulation of the electrotonic structure of Aplysia neurons by subthreshold voltage shifts and serotonin. Soc. Neurosci. Abstr. 14: 384, 1988.

STRUMWASSER, F. The demonstration and manipulation of a circadian rhythm in a single neuron. In: Circadian Clocks, edited by J. Aschoff. Amsterdam: North-Holland, 1965, p. 442-462.

SYED, N. I., LUKOWIAK, K., AND BuLLOCH, A. G. M. In vitro reconstruction of the respiratory central pattern generator of the mollusc Lymnaea. Science Wash. DC 250, 282-285, 1990.

TOSAKA, T., CHICHIBU, S., AND LiBET, B. Intracellular analysis of slow inhibitory and excitatory postsynaptic potentials in sympathetic ganglia of the frog. J. Neurophysiol. 31: 396-408, 1968.

Ts'o, D. Y., GilbeRT, C. D., AND WIESEL, T. N. Relationships between horizontal interactions and functional architecture in cat striate cortex as revealed by cross-correlation analysis. J. Neurosci. 6: 1160-1170, 1986.

WACHTEL, H. AND KaNDEL, E. R. Conversion of synaptic excitation to inhibition at a dual chemical synapse. J. Neurophysiol. 34: 56-68, 1971.

WoOlum, J. C. AND Strumwasser, F. Membrane-potential-sensitive dyes for optical monitoring of activity in Aplysia. J. Neurobiol. 9: 185193, 1978.

Yagodin, S. V., Slutsky, V. M., Suhanov, V. L., Slonimsky, Y. L., Stolovicky, V. M., VAlyuhov, V. P., AND PoPOV, S. V. Spatio-temporal characteristics of potential-dependent optical signals of molluscan ganglia obtained with 100-element photodiode array. Dokl. Acad. Sci. USSR 298: 1497-1502, 1988.

ZeCEVIC, D., Wu, J.-Y., Cohen, L. B., London, J., HopP, H. P., AND FALK, C. X. Hundreds of neurons in the Aplysia abdominal ganglion are active during the gill-withdrawal reflex. J. Neurosci. 9: 3681-3689, 1989. 